\title{
Cochrane
}

Library

Cochrane Database of Systematic Reviews

\section{Standard versus biofilm antimicrobial susceptibility testing to guide antibiotic therapy in cystic fibrosis (Review)}

\section{Waters V, Ratjen F}

Waters V, Ratjen F.

Standard versus biofilm antimicrobial susceptibility testing to guide antibiotic therapy in cystic fibrosis. Cochrane Database of Systematic Reviews 2017, Issue 10. Art. No.: CD009528. DOI: 10.1002/14651858.CD009528.pub4. 
TABLE OF CONTENTS

HEADER 1

ABSTRACT

PLAIN LANGUAGE SUMMARY

SUMMARY OF FINDINGS

BACKGROUND

OBJECTIVES

METHODS

RESULTS

DISCUSSION

AUTHORS' CONCLUSIONS

ACKNOWLEDGEMENTS

REFERENCES

CHARACTERISTICS OF STUDIES

DATA AND ANALYSES

Analysis 1.1. Comparison 1 Biofilm testing versus standard testing, Outcome $1 \mathrm{FEV}_{1}(\mathrm{~L})$ change from start of treatment.

Analysis 1.2. Comparison 1 Biofilm testing versus standard testing, Outcome $2 \mathrm{FEV}_{1}$ (\% predicted) change from start of treatment.

Analysis 1.3. Comparison 1 Biofilm testing versus standard testing, Outcome 3 FVC (\% predicted) change from start of treatment.

Analysis 1.4. Comparison 1 Biofilm testing versus standard testing, Outcome 4 FVC (L) change from start of treatment. ...........

Analysis 1.5. Comparison 1 Biofilm testing versus standard testing, Outcome 5 Time to next exacerbation (days).

Analysis 1.6. Comparison 1 Biofilm testing versus standard testing, Outcome 6 Pulmonary exacerbations (number of participants)

Analysis 1.7. Comparison 1 Biofilm testing versus standard testing, Outcome 7 Adverse events.

Analysis 1.8. Comparison 1 Biofilm testing versus standard testing, Outcome 8 Change in P aeruginosa sputum density (log 10 CFU/g).

Analysis 1.9. Comparison 1 Biofilm testing versus standard testing, Outcome 9 CFQ-R change from start of treatment. ........... WHAT'S NEW

HISTORY

CONTRIBUTIONS OF AUTHORS

DECLARATIONS OF INTEREST

SOURCES OF SUPPORT

DIFFERENCES BETWEEN PROTOCOL AND REVIEW

INDEX TERMS

1

2

3

6

6 
[Intervention Review]

\section{Standard versus biofilm antimicrobial susceptibility testing to guide antibiotic therapy in cystic fibrosis}

Valerie Waters $^{1}$, Felix Ratjen ${ }^{2}$

1Department of Pediatrics, Division of Infectious Diseases, Hospital for Sick Children, Toronto, Canada. 2Department of Pediatrics, The Hospital for Sick Children, Toronto, Canada

Contact address: Valerie Waters, Department of Pediatrics, Division of Infectious Diseases, Hospital for Sick Children, 555 University Avenue, Toronto, ON, M5G 1X8, Canada. valerie.waters@sickkids.ca.

Editorial group: Cochrane Cystic Fibrosis and Genetic Disorders Group.

Publication status and date: Edited (no change to conclusions), published in Issue 3, 2020.

Citation: Waters V, Ratjen F. Standard versus biofilm antimicrobial susceptibility testing to guide antibiotic therapy in cystic fibrosis. Cochrane Database of Systematic Reviews 2017, Issue 10. Art. No.: CD009528. DOI: 10.1002/14651858.CD009528.pub4.

Copyright (c) 2020 The Cochrane Collaboration. Published by John Wiley \& Sons, Ltd.

\section{A B S T R A C T}

\section{Background}

The antibiotics used to treat pulmonary infections in people with cystic fibrosis are typically chosen based on the results of antimicrobial susceptibility testing performed on bacteria traditionally grown in a planktonic mode (grown in a liquid). However, there is considerable evidence to suggest that Pseudomonas aeruginosa actually grows in a biofilm (or slime layer) in the airways of people with cystic fibrosis with chronic pulmonary infections. Therefore, choosing antibiotics based on biofilm rather than conventional antimicrobial susceptibility testing could potentially improve response to treatment of Pseudomonas aeruginosa in people with cystic fibrosis. This is an update of a previously published Cochrane Review.

\section{Objectives}

To compare biofilm antimicrobial susceptibility testing-driven therapy to conventional antimicrobial susceptibility testing-driven therapy in the treatment of Pseudomonas aeruginosa infection in people with cystic fibrosis.

\section{Search methods}

We searched the Cochrane Cystic Fibrosis Trials Register, compiled from electronic database searches and handsearching of journals and conference abstract books. Most recent search: 19 June 2017.

We also searched two ongoing trials registries and the reference lists of relevant articles and reviews. Most recent searches: 24 August 2017 and 05 September 2017.

\section{Selection criteria}

Randomized controlled trials of antibiotic therapy based on biofilm antimicrobial susceptibility testing compared to antibiotic therapy based on conventional antimicrobial susceptibility testing in the treatment of Pseudomonas aeruginosa pulmonary infection in people with cystic fibrosis.

\section{Data collection and analysis}

Both authors independently selected trials, assessed their risk of bias and extracted data from eligible trials. Additionally, the review authors contacted the trial investigators to obtain further information. The quality of the evidence was assessed using the GRADE criteria. 


\section{Main results}

The searches identified two multicentre, randomized, double-blind controlled clinical trials eligible for inclusion in the review with a total of 78 participants (adults and children); one trial was done in people who were clinically stable, the other in people experiencing pulmonary exacerbations. These trials prospectively assessed whether the use of biofilm antimicrobial susceptibility testing improved microbiological and clinical outcomes in participants with cystic fibrosis who were infected with Pseudomonas aeruginosa. The primary outcome was the change in sputum Pseudomonas aeruginosa density from the beginning to the end of antibiotic therapy.

Although the intervention was shown to be safe, the data from these two trials did not provide evidence that biofilm susceptibility testing was superior to conventional susceptibility testing either in terms of microbiological or lung function outcomes. One of the trials also measured risk and time to subsequent exacerbation as well as quality of life measures and did not demonstrate any difference between groups in these outcomes. Both trials had an overall low risk of bias and the quality of the evidence using GRADE criteria was deemed to be moderate to high for the outcomes selected.

\section{Authors' conclusions}

The current evidence is insufficient to recommend choosing antibiotics based on biofilm antimicrobial susceptibility testing rather than conventional antimicrobial susceptibility testing in the treatment of Pseudomonas aeruginosa pulmonary infections in people with cystic fibrosis. Biofilm antimicrobial susceptibility testing may be more appropriate in the development of newer, more effective formulations of drugs which can then be tested in clinical trials.

\section{PLAIN LANGUAGE SUMMARY}

\section{Standard versus biofilm antibiotic testing to guide antibiotic treatment in cystic fibrosis}

\section{Review question}

We reviewed evidence to see whether it is better to test antibiotics on Pseudomonas aeruginosa bacteria (bugs) grown in a layer of slime (a biofilm) or on those grown in liquid, when deciding which antibiotics to use for treating a flare up of symptoms in people with cystic fibrosis. We wanted to know if either method would lead to better antibiotic choices with better clinical outcomes.

\section{Background}

Long-term lung infection is the main cause of death in people with cystic fibrosis. Antibiotic treatments for these infections have helped people with cystic fibrosis live longer. Doctors usually choose which antibiotics to use after on testing them against bacteria grown from samples taken from the infected person. These bacteria are grown in a liquid in the laboratory; but in real life bacteria such as Pseudomonas aeruginosa do not grow in liquid in the lungs of people with cystic fibrosis, instead they grow in a slime layer called a biofilm. Laboratory testing of antibiotics against Pseudomonas aeruginosa grown in a biofilm rather than in a liquid may give results that lead to better antibiotic choices with better clinical outcomes when treating pulmonary infections in people with cystic fibrosis.

\section{Search date}

We last looked for evidence on 19 June 2017.

\section{Study characteristics}

We included two trials, one run in the USA (in people who were clinically stable) and one run in Canada (in people who were having an exacerbation or respiratory flare up). A total of 78 people from these trials gave sputum samples. Bacteria from these samples were grown in either a liquid (34 samples) or biofilm (44 samples) with an equal chance of being grown in either one. Neither the individuals or their clinicians knew before or during the trial which method had been used for the sample from each person. A mixture of adults and children took part in the trials, with the average age being around 20 to 30 years. There were an equal number of men and women in both trials. Around half the people in the trials had two copies of the delta F508 gene and there were almost equal number of these in each group. Average lung function in both groups was similar.

\section{Key results}

The main outcome of both trials was the decrease in the amount of bacteria in the sputum of people in each group after antibiotic treatment. There was no difference in the levels of bacteria found in the sputum or in the improvement in lung function between the two groups in either trial. In both trials, there was a similar number of individuals in each group who had either a mild or moderate side effect. There were no serious side effects reported by anyone in either study. The evidence does not show that one method of testing is better than the other and that people receiving antibiotics chosen on the basis of either method have equal chances of any side effects.

\section{Quality of the evidence}

The quality of the evidence was quite good as people had equal chances of being in either group and they did not know which testing group they were in. This means we don't think the trial results would have been affected because of this. 


\begin{tabular}{|c|c|c|c|c|c|c|c|}
\hline \multirow{9}{*}{ 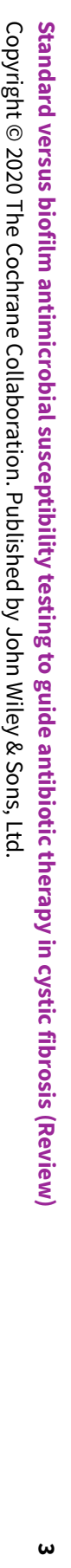 } & \multicolumn{7}{|c|}{$\begin{array}{l}\text { S U M M ARY O F F I N D I N G S } \\
\text { Summary of findings for the main comparison. }\end{array}$} \\
\hline & \multicolumn{7}{|c|}{ Biofilm antimicrobial susceptibility testing compared with standard antimicrobial susceptibility testing for guiding antibiotic therapy in cystic fibrosis } \\
\hline & \multicolumn{7}{|c|}{$\begin{array}{l}\text { Patient or population: adults and children with cystic fibrosis and } P \text { aeruginosa } \\
\text { Settings: outpatients } \\
\text { Intervention: antibiotics chosen on the basis of biofilm antimicrobial susceptibility testing } \\
\text { Comparison: antibiotics chosen on the basis of standard antimicrobial susceptibility testing }\end{array}$} \\
\hline & \multirow[t]{3}{*}{ Outcomes } & \multicolumn{2}{|l|}{ Illustrative comparative risks* $(95 \% \mathrm{CI})$} & \multirow{3}{*}{$\begin{array}{l}\text { Relative ef- } \\
\text { fect } \\
(95 \% \mathrm{Cl})\end{array}$} & \multirow{3}{*}{$\begin{array}{l}\text { No of partici- } \\
\text { pants } \\
\text { (studies) }\end{array}$} & \multirow{3}{*}{$\begin{array}{l}\text { Quality of the } \\
\text { evidence } \\
\text { (GRADE) }\end{array}$} & \multirow[t]{3}{*}{ Comments } \\
\hline & & Assumed risk & $\begin{array}{l}\text { Corresponding } \\
\text { risk }\end{array}$ & & & & \\
\hline & & $\begin{array}{l}\text { Standard antimicrobial susceptibili- } \\
\text { ty testing }\end{array}$ & $\begin{array}{l}\text { Biofilm antimi- } \\
\text { crobial suscepti- } \\
\text { bility testing }\end{array}$ & & & & \\
\hline & $\begin{array}{l}\text { FEV } 1 \text { change from start of } \\
\text { treatment }(\mathrm{L}) \\
\text { Follow-up: } 14 \text { days }\end{array}$ & $\begin{array}{l}\text { The mean change in } \mathrm{FEV}_{1} \text { ranged } \\
\text { across control groups from } 0.12 \mathrm{~L} \text { to } \\
2.75 \mathrm{~L} \text {. }\end{array}$ & $\begin{array}{l}\text { The mean change } \\
\text { in } \mathrm{FEV}_{1} \text { in the in- } \\
\text { tervention groups } \\
\text { was } \\
0.04 \mathrm{~L} \text { higher } \\
\text { ( } 0.08 \mathrm{~L} \text { lower to } \\
0.16 \mathrm{~L} \text { higher). }\end{array}$ & NA & $\begin{array}{l}68 \\
(2)\end{array}$ & $\begin{array}{l}\oplus \oplus \oplus \oplus \\
\text { high }\end{array}$ & \\
\hline & $\begin{array}{l}\mathrm{FEV}_{1} \text { change from start of } \\
\text { treatment (\% predicted) } \\
\text { Follow-up: } 14 \text { days }\end{array}$ & $\begin{array}{l}\text { The mean }(\mathrm{SD}) \text { change in } \mathrm{FEV}_{1} \text { in the } \\
\text { control group was } 9.62(10.12) \% \text { pre- } \\
\text { dicted. }\end{array}$ & $\begin{array}{l}\text { The mean change } \\
\text { in } \mathrm{FEV}_{1} \text { in the in- } \\
\text { tervention groups } \\
\text { was } \\
2.47 \% \text { lower } \\
\text { (9.29\% lower to } \\
4.34 \% \text { higher). }\end{array}$ & NA & $\begin{array}{l}34 \\
(1)\end{array}$ & $\begin{array}{l}\oplus \oplus \oplus \ominus \\
\text { moderate }^{1}\end{array}$ & $\begin{array}{l}\text { Data provided by the } \\
\text { authors for this out- } \\
\text { come. }\end{array}$ \\
\hline & $\begin{array}{l}\text { Time to next exacerbation } \\
\text { Follow-up: } 5 \text { years }\end{array}$ & \multicolumn{2}{|c|}{$\begin{array}{l}\text { The median time to subsequent exacerbation was } 185 \text { days } \\
\text { in the standard testing group and } 162 \text { days in the biofilm } \\
\text { group. The difference in survival curves was not significant } \\
(P=0.8) \text {. }\end{array}$} & NA & $\begin{array}{l}39 \\
(1)\end{array}$ & $\begin{array}{l}\oplus \oplus \oplus \ominus \\
\text { moderate }^{1}\end{array}$ & \\
\hline
\end{tabular}




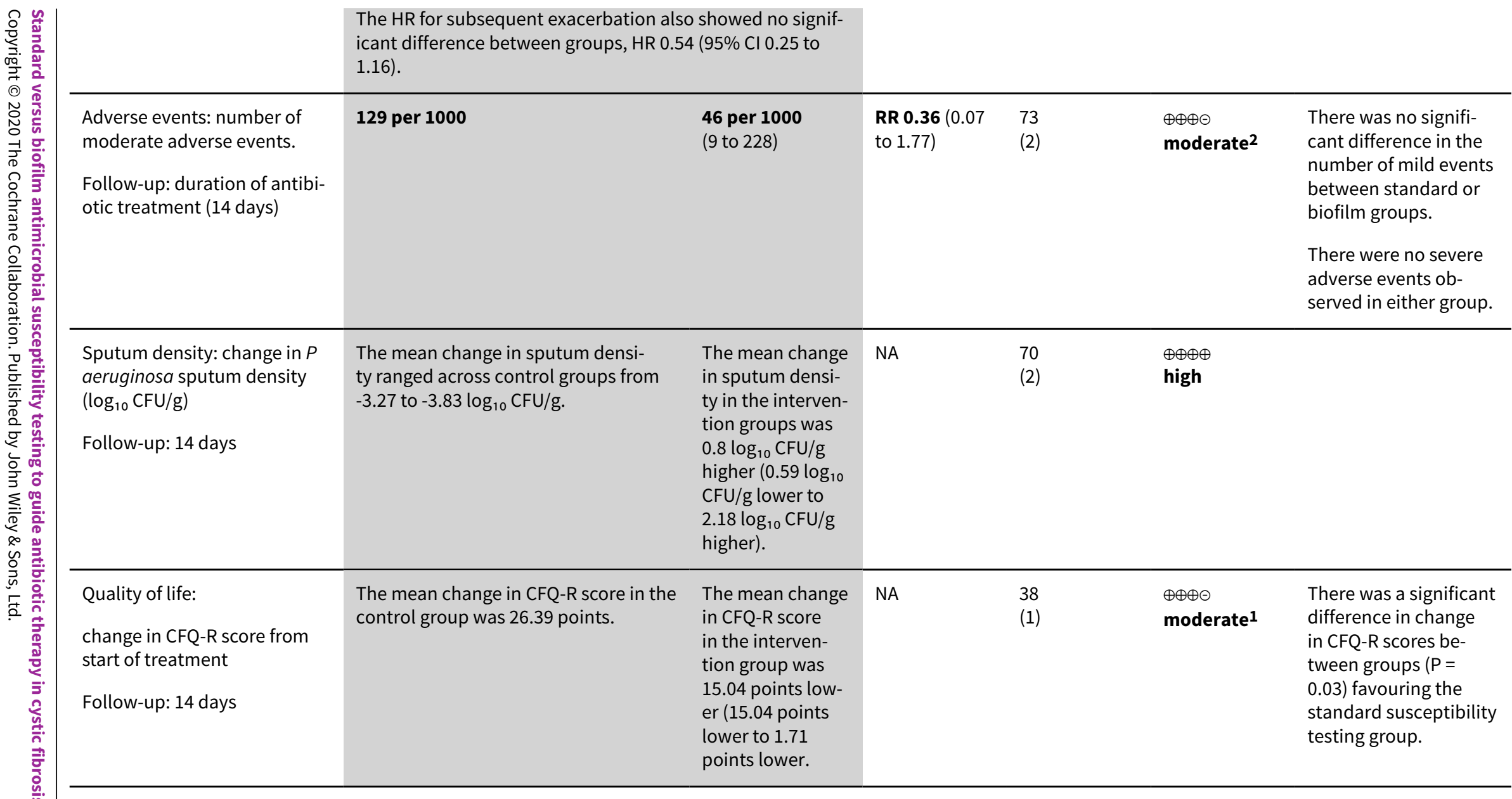

*The basis for the assumed risk (e.g. the median control group risk across studies) is provided in footnotes. The corresponding risk (and its $95 \%$ confidence interval) is based on the assumed risk in the comparison group and the relative effect of the intervention (and its $95 \% \mathrm{Cl}$ ).

CFQ-R: Cystic Fibrosis Questionnaire - Revised; CFU: colony forming units; CI: confidence interval; FEV $\mathbf{F}_{1}$ : forced expiratory volume in 1 second; HR: hazard ratio; P aeruginosa: Pseudomonas aeruginosa; RR: risk ratio; SD: standard deviation.

GRADE Working Group grades of evidence

High quality: Further research is very unlikely to change our confidence in the estimate of effect.

Moderate quality: Further research is likely to have an important impact on our confidence in the estimate of effect and may change the estimate.

Low quality: Further research is very likely to have an important impact on our confidence in the estimate of effect and is likely to change the estimate. Very low quality: We are very uncertain about the estimate.

1. Downgraded once due to small number of participants from 1 trial. 

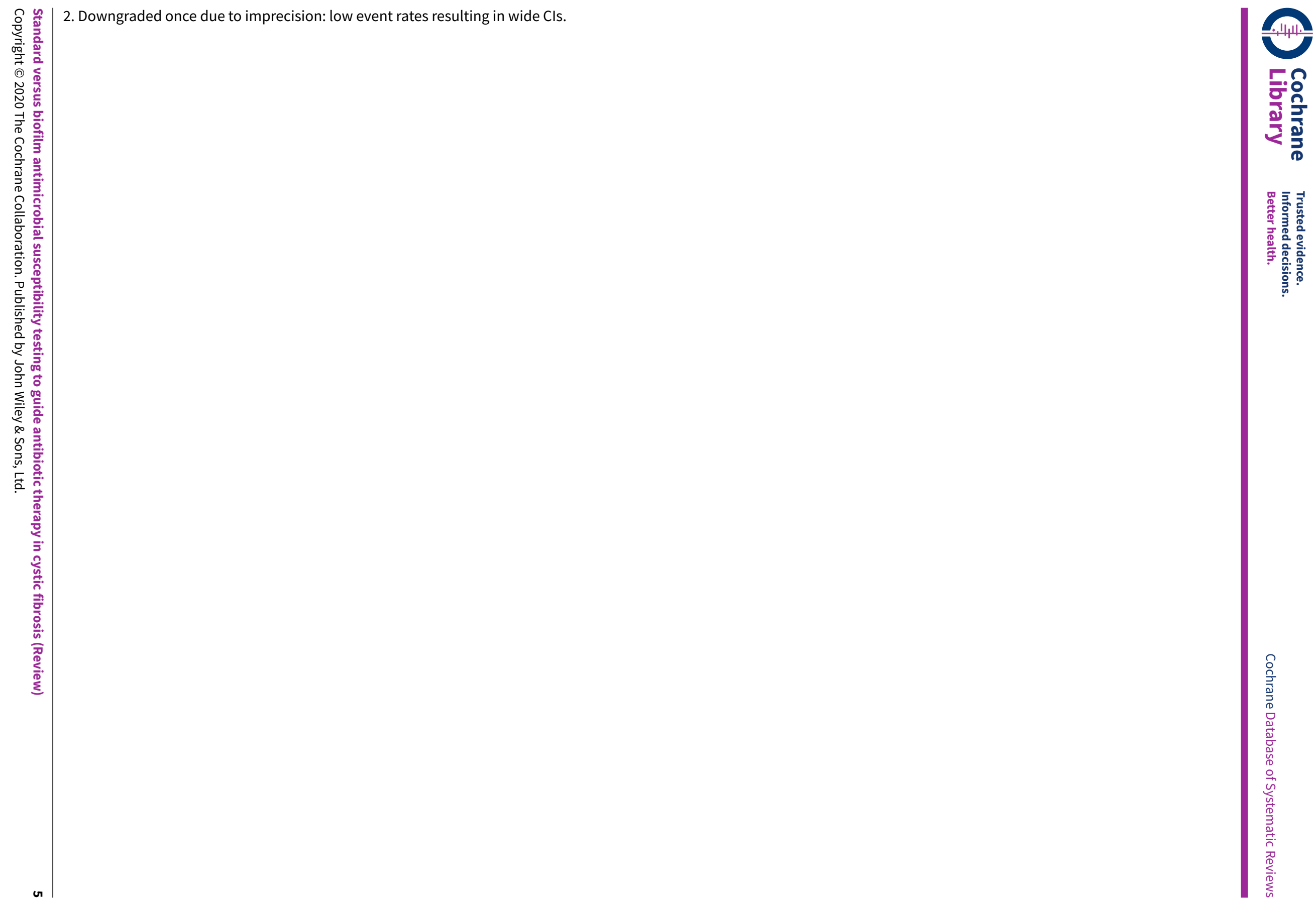


\section{B A C K G R O U N D}

\section{Description of the condition}

Cystic fibrosis (CF) is the most common life-limiting genetic disorder in white populations. Respiratory failure secondary to chronic bacterial respiratory infection is the leading cause of death in CF (Gibson 2003). One of the most important bacteria that infect the airways of people with CF is Pseudomonas aeruginosa (P aeruginosa) (Burns 2001; Henry 1992; Kosorok 2001; Pamukcu 1995). More aggressive use of antibiotic therapy to treat these infections is considered to be an important factor for the improved survival seen in people with CF (Frederiksen 1996; Ramsey 1996). The antibiotics used to treat pulmonary infections in CF are typically chosen based on the results of antimicrobial susceptibility testing done in the laboratory (Waters 2008). Although the length of antibiotic treatment may vary, acute pulmonary exacerbations are typically treated with intravenous antibiotics for 14 days.

\section{Description of the intervention}

In the laboratory, bacteria are cultured from respiratory tract specimens obtained from people with CF. The bacteria are then traditionally grown in a planktonic mode (grown in a liquid) and exposed to fixed concentrations of different antibiotics (Jorgensen 2009). The potential efficacy of antibiotics is then determined by measuring their ability to inhibit the growth of these bacteria. Each bacterium is then reported to be susceptible, intermediate or resistant to each tested antibiotic. Clinicians would subsequently choose antibiotics, to which the bacterium is susceptible, to treat their patients. This type of conventional antimicrobial susceptibility testing based on planktonic growth of bacteria has been validated in the treatment of urinary tract and blood stream infections, in which susceptibility results correlate well with clinical outcomes (MacGowan 2008). This is not the case for the treatment of pulmonary infections in CF (Gilligan 2006). Trials have shown that there is not any association between conventional antimicrobial susceptibility results and clinical outcomes, in terms of lung function, following the administration of antibiotics for a pulmonary exacerbation (Smith 2003). In addition, susceptibility testing is typically done on one colony selected from a similar appearing growth of an organism (morphotype). However, different colonies from the same morphotype of $P$ aeruginosa grown from a CF sputum sample, for example, may have different antimicrobial susceptibility results, making it difficult to evaluate the role of conventional susceptibility testing in CF (Foweraker 2005).

In fact, there is considerable in vitro and in vivo evidence to suggest that $P$ aeruginosa actually grows in a biofilm (or slime layer) in the airways of people with CF with chronic pulmonary infections (Murray 2007; Drenkard 2002; Singh 2000). Biofilms are communities of bacteria embedded in an exopolysaccharide matrix (coating of sugar molecules) that make them more resistant to antimicrobial killing (Prince 2002). In the laboratory, bacteria are usually grown as a biofilm by growing them on plastic pegs (Ceri 1999). In order to perform biofilm antimicrobial susceptibility testing, the bacteria are then exposed to antibiotics by placing the plastic pegs into wells (usually in a 96-well plate) containing different antibiotics at fixed concentrations. The ability of the antibiotic to inhibit or kill the bacteria in a biofilm can be determined by a variety of methods. There are limitations to this system however. In contrast to this assay (or test) that grows $P$ aeruginosa on plastic pegs, trials have shown that $P$ aeruginosa actually forms a biofilm within the mucous itself (Bjarnsholt 2009). In addition, in this assay, $P$ aeruginosa is grown under aerobic conditions but there is considerable evidence that organisms grow within an anaerobic environment in the CF lung (Tielen 2010).

Biofilm antimicrobial susceptibility testing has generally been done in research settings. There is, however, a commercially available biofilm antimicrobial susceptibility panel, called BioFILM $\mathrm{PA}^{\mathrm{TM}}$ (Innovotech Inc), which is licensed by Health Canada for antimicrobial susceptibility testing of $P$ aeruginosa.

\section{How the intervention might work}

It would thus seem logical to reason that antimicrobial susceptibilities determined for bacteria growing as a biofilm, rather than planktonically, would lead to more reliable antibiotic choices in treating $P$ aeruginosa in the CF airway. Previous use of biofilm susceptibility assays for isolates of $P$ aeruginosa from people with CF have shown that antimicrobial susceptibilities based on biofilm growth differ significantly from those based on planktonic growth. In one trial, biofilm inhibitory concentrations (concentrations of antibiotics that inhibit biofilm growth) for $P$ aeruginosa were much higher than the corresponding conventionally determined minimum inhibitory concentrations (MICs) for several classes of antibiotics including ß-lactams (Moskowitz 2004), leading to different simulated antibiotic regimens (Moskowitz 2005). Using a similar biofilm antimicrobial susceptibility assay, the Calgary Biofilm Device, minimal biofilm eradication concentrations of selected antibiotics were found to be 100 to 1000 times the MICs for certain organisms including $P$ aeruginosa (Ceri 1999). Hence, antibiotic susceptibilities based on biofilm-grown $P$ aeruginosa may lead to different antibiotic choices with potentially improved microbiological and clinical outcomes.

\section{Why it is important to do this review}

Antibiotic therapy plays an important part in maintaining the health and longevity of people with CF. However, there is currently no way of choosing antibiotic therapy in CF that is known to result in improved clinical outcomes. Conventional antimicrobial susceptibility testing may not accurately reflect how bacteria grow in the CF lung; biofilm antimicrobial susceptibility testing may be a better methodology, leading to improved clinical outcomes and less adverse effects. To answer this question, this review compared biofilm antimicrobial susceptibility testingdriven therapy to conventional antimicrobial susceptibility testingdriven therapy in the treatment of $P$ aeruginosa infection in people with CF.

This is an updated version of a previously published Cochrane Review (Waters 2012; Waters 2015).

\section{O B JECT IVES}

To compare biofilm antimicrobial susceptibility testing-driven therapy to conventional antimicrobial susceptibility testing-driven therapy in the treatment of $P$ aeruginosa infection in people with CF. 


\section{METHODS}

\section{Criteria for considering studies for this review}

\section{Types of studies}

Randomized controlled trials (RCTs).

\section{Types of participants}

Adults and children (with all levels of disease severity) diagnosed with CF, confirmed with sweat test or genetic testing (or both), who have $P$ aeruginosa isolated from respiratory specimens. Respiratory tract specimens include sputum, throat swabs or bronchoalveolar lavage specimens.

\section{Types of interventions}

Biofilm antimicrobial susceptibility testing-driven therapy compared to conventional antimicrobial susceptibility testingdriven therapy in the treatment of $P$ aeruginosa infection in people with CF. Therapy includes single or multiple antibiotics, oral, inhaled or intravenous antibiotics.

\section{Types of outcome measures}

\section{Primary outcomes}

1. Lung function

a. forced expiratory volume at one second $\left(\mathrm{FEV}_{1}\right)$ (absolute values or change from start of treatment (post hoc change) (liters or per cent (\%) predicted or both))

b. forced vital capacity (FVC) (absolute values or change from start of treatment (post hoc change) (liters or $\%$ predicted or both))

c. mid-expiratory flow $\left(\mathrm{FEF}_{25-75 \%}\right)$ (absolute values or change from start of treatment (post hoc change) (liters or \% predicted or both))

2. Pulmonary exacerbations, defined as an increase in respiratory symptoms requiring antibiotic therapy (Fuchs 1994)

a. number of pulmonary exacerbations

b. time between pulmonary exacerbations

c. time to subsequent exacerbation

3. Adverse events (including numbers of events, proportion of participants withdrawing and proportion of participants changing therapy)

a. mild: transient event, no treatment change, e.g. rash

b. moderate: treatment discontinued, e.g. nephrotoxicity

c. severe: causing hospitalization or death

\section{Secondary outcomes}

1. Sputum bacterial density (measured in colony forming units $/ \mathrm{ml}$ (CFU/ml))

2. Quality of life (QoL) (as measured by a validated $\mathrm{QoL}$ score i.e. CFQoL (Gee 2000), CFQ-R (Quittner 2009))

3. Mortality

4. Nutritional parameters
a. weight
b. height
c. body mass index (BMI)

5. Number of hospitalizations

6. Use of oral antibiotics

\section{Search methods for identification of studies}

We searched for all relevant published and unpublished trials without restrictions on language, year or publication status.

\section{Electronic searches}

We identified relevant trials from the Group's Cystic Fibrosis Trials Register using the terms: antibiotics susceptibility (sensitivity) testing.

The Cystic Fibrosis Trials Register is compiled from electronic searches of the Cochrane Central Register of Controlled Trials (CENTRAL) (updated each new issue of the Cochrane Library), weekly searches of MEDLINE, a search of Embase to 1995 and the prospective handsearching of two journals - Pediatric Pulmonology and the Journal of Cystic Fibrosis. Unpublished work is identified by searching the abstract books of three major cystic fibrosis conferences: the International Cystic Fibrosis Conference; the European Cystic Fibrosis Conference and the North American Cystic Fibrosis Conference. For full details of all searching activities for the register, please see the relevant sections of the website.

Date of last search of the Group's Cystic Fibrosis Trials Register: 19 June 2017.

We also checked the National Institutes of Health (NIH) sponsored website www.clinicaltrials.gov for any ongoing trials with potential interim results using the search terms 'cystic fibrosis' and 'biofilm'. Most recent search: 24 August 2017.

We searched the WHO ICTRP (apps.who.int/trialsearch/ default.aspx) using the terms 'cystic fibrosis' and 'biofilm'. Most recent search: 05 September 2017.

\section{Searching other resources}

We checked the reference lists of all trials identified for any further relevant trials. We also contacted biotech companies that are involved with biofilm antimicrobial susceptibility technology for any additional information.

\section{Data collection and analysis}

\section{Selection of studies}

The two authors (VW, FR) independently applied the inclusion criteria to all potential trials. The authors were not blinded to the trials. If a disagreement had occurred, the authors would have resolved this by discussion with a third person (Nikki Jahnke (NJ)). For one trial on which the two review authors were co-investigators (Yau 2014), two employees at the Cystic Fibrosis and Genetic Disorders Group's editorial base (NJ, Sarah Nolan (SN)) confirmed eligibility for inclusion.

\section{Data extraction and management}

Using a data collection form, two authors (VW, FR) independently recorded data obtained from published reports or from trial investigators. If a disagreement had occurred, they would have resolved it by discussion with a third person (NJ). For the trial included at the 2015 update in which both review authors were active investigators (Yau 2014), two independent people (NJ, SN) extracted data. In addition to information about trial references, authors and verification of trial eligibility, the data collection form included information about the methods of the trial (e.g. trial 
duration, type of trial (e.g. RCT), blinding, number of dropouts and potential confounders). The authors also reported characteristics of the trial participants including age, sex and setting of the trial on the form. Furthermore, they also described the intervention with regards to type of antibiotic, route of delivery, doses and length of treatment. The authors collected data for all randomized participants. The authors attempted to collect the following data: the mean change (before and after antibiotic therapy) in $\mathrm{FEV}_{1}$ and $\mathrm{FVC}, \mathrm{FEF}_{25-75 \%}$; the mean hospital length of stay and number of hospitalizations; the time to subsequent pulmonary exacerbation; the number of adverse events; the mean QoL score after antibiotic therapy; the mean change in sputum bacterial density (before and after antibiotic therapy); the number of mortalities; change in weight (before and after antibiotic therapy); and the number of days of oral antibiotic use. For each mean value, the authors also obtained the standard deviation (SD) (variation from the average). For time-to-next exacerbation, they tried to obtain logrank estimates and Cox model estimates.

The authors planned to measure outcomes at less than a week, one to two weeks, more than two weeks to three weeks, more than three weeks to four weeks and at monthly intervals, if applicable. They have actually reported data at Day 7, Day 14 and one month. They would have measured the outcome 'Time to next pulmonary exacerbation' in monthly intervals after these time points; however given the data which are available from the Yau trial (Yau 2014), they have reported this outcome as a hazard ratio (HR) in days. In future updates, they will also consider outcomes measured at other time points.

\section{Assessment of risk of bias in included studies}

Two authors (VW, FR) independently assessed the included trials for the following types of bias: selection bias (bias in choosing trial participants); performance bias (bias in the care of trial participants); attrition bias (bias in how participants who are lost to follow up are handled); detection bias (biased assessment of outcome); and reporting bias (bias in the reporting of trial outcomes) using the following strategies as outlined below (Higgins 2011a). For the Yau trial, two independent people (NJ, SN) assessed the risks of bias since both review authors were active investigators on the trial (Yau 2014).

\section{Assessment of generation of allocation sequences}

They assessed each trial as to the generation of allocation sequences:

1. low risk of bias: if allocation sequence is suitable to prevent selection bias (i.e. random numbers table, drawing envelopes, tossing a coin, throwing dice, etc);

2. high risk of bias: if allocation sequence could be related to prognosis and thus introduce selection bias (i.e. assigning participants based on case record number, date of birth, date of admission, etc);

3. unclear risk of bias: if the trial is described as randomised but the method used to generate the allocation sequence is not stated.

\section{Assessment of concealment of allocation sequences}

They also assessed the method used to conceal the allocation sequences in each trial:
1. low risk of bias: if participants and investigators cannot predict which group the participant will be assigned to (i.e. coded drug containers, central randomisation, numbered, sealed, opaque envelopes, etc);

2. high risk of bias: if participants and investigators can predict which group the participant will be assigned to and thus introduce selection bias (i.e. open allocation schedule, nonopaque envelopes, etc);

3. unclear risk of bias: if the method of concealing the allocation sequence is not described.

\section{Assessment of blinding}

In order to determine the potential for performance and detection bias, the authors assessed each trial with respect to the degree of blinding:

1. the participant is blinded to participant assignment;

2. the care provider is blinded to participant assignment;

3. the investigator measuring trial outcomes is blinded to participant assignment.

They considered there to be a high risk of bias if there was no blinding with respect to one or more of the above categories. They considered there to be a low risk of bias if the trial was blinded to all three. They considered there to be an unclear risk of bias if the trial did not specify the degree of blinding in each of the three categories.

\section{Incomplete outcome data}

To assess for the possibility of attrition bias, the authors examined each trial with respect to:

1. whether or not it was stated how many participants were lost to follow-up and why they were lost to follow-up;

2. whether or not an intention-to-treat analysis was used (i.e. inclusion in the final analysis of all randomised participants into a trial in the groups to which they were randomised irrespective of what happened subsequently).

They considered there to be a high risk of bias if an intention-totreat analysis was not used. They considered there to be a low risk of bias if the number and reason for loss of follow-up was specified and if an intention-to-treat analysis was used. They considered there to be an unclear risk of bias if the trial did not specify the above outlined information.

\section{Assessment of selective reporting}

The authors reviewed the included trials for selective reporting (Higgins 2011a). They compared the original trial protocol with the published paper to ensure all planned outcomes were reported. If, for trials the authors may include in the future, the original trial protocols are not available, they will review the 'Methods' and 'Results' sections and the authors will use their discretion to determine if selective reporting has occurred.

\section{Assessment of other potential sources of bias}

The authors also reviewed the included trials for other potential sources of bias that could have threatened the validity of the trial. These included: early cessation of the trial; if the interim results affect the trial conduct; deviation from the trial protocol; 
inappropriate administration of a co-intervention; contamination; the use of an insensitive instrument to measure outcomes; selective reporting of subgroups; fraud; inappropriate influence of funding agencies and industry sponsorship; null bias due to the interventions being poorly delivered; or the existence of a prerandomization of an intervention that could affect the effects of the randomized intervention (Higgins 2011a).

\section{Incorporating assessments of trial validity in reviews}

For future updates, the authors plan to weigh trials according to their assessed validity by using the inverse of the variance for the estimated measure of effect. If they consider there is a high risk of bias, they will investigate the effects of this with a sensitivity analysis (see below).

\section{Measures of treatment effect}

For dichotomous data, the authors gathered information on participants randomized to each treatment group, based on an intention-to-treat analysis, and the number of events. For future updates, they plan to include interim results from individual randomized participants from ongoing trials in the analysis. The authors defined time points for each trial outcome according to when it was measured (see above 'Data extraction and management'). They analyzed trial outcomes separately according to these time points. In future updates and if data are available from multiple trials, they plan to pool the treatment effect across trials to determine a risk ratio (RR) and its $95 \%$ confidence intervals (Cls) for each trial outcome.

For continuous data, the authors calculated the difference between the mean (average) values (MD) of treatment effect for each group. For future summary statistics across trials, they will use the MD if the same scale is used, or the standardized mean difference (SMD) if different scales are used (e.g. quality of life measurements) both with 95\% Cls. For time-to-event data, most trials use Kaplan-Meier survival analysis. The authors will thus collect log-rank estimates and Cox model estimates to subsequently summarize the time-toevent data as a HR with 95\% Cls (Higgins 2011b; Parmar 1998). Data provided by the investigators on the Yau trial, allowed the calculation of the log HR and standard error for the outcome 'Time to next pulmonary exacerbation' which the authors analysed using the generic inverse variance.

\section{Unit of analysis issues}

All analyses were performed at the unit of the participants. In one trial, participants who experienced an exacerbation during the study were re-randomised to either conventional or biofilm antimicrobial susceptibility testing and results were reported at the unit of analysis of exacerbations rather than participants (Yau 2014). The authors of the trial were able to provide raw data for the outcomes of interest recorded for this review and result at the unit of the participant were calculated.

In future updates, the authors will include data from future cluster-randomized trials if the information is available. For clusterrandomized trials, they will calculate the intracluster correlation coefficient (ICC) according to Donner (Donner 2001). They will also include data from cross-over trials if the information is available. They will analyze continuous data from cross-over trials using one of three approaches: treat the trial as a parallel trial and pool the interventional periods and compare these to the pooled placebo periods; include data from the first period only and approximate a paired analysis; or impute missing SDs (Sterne 2011). Crossover trials with dichotomous outcomes require more complicated methods and the authors plan to consult with a statistician as recommended (Elbourne 2002).

\section{Dealing with missing data}

Whether or not outcome data are actually collected, in reality, timepoint data are often missing for participants who are lost to follow up. The authors performed an available-case analysis (analyzing data for every participant for whom the outcome is obtained) in these situations. They reported the percentages of participants from whom no outcome data were obtained on the data collection form. They included data on only those whose results are known, using as a denominator the total number of people who completed the trial for the particular outcome in question. In future, if more trials are included, the authors will consider variation in the degree of missing data across trials as a potential source of heterogeneity.

\section{Assessment of heterogeneity}

For future meta-analyses, the authors will measure the variability of results between trials (heterogeneity) using the $\mathrm{Chi}^{2}$ test (where a $P$ value of less than 0.10 indicates the presence of heterogeneity) (Higgins 2011b) and the $\mathrm{I}^{2}$ method outlined by Higgins (Higgins 2003). The $I^{2}$ statistic describes the percentage of total variation across trials that is due to heterogeneity rather than by chance. It is calculated using Cochran's heterogeneity statistic and the degrees of freedom. The $\mathrm{I}^{2}$ statistic can range from $0 \%$ to $100 \%$. A value of $0 \%$ indicates no observed heterogeneity and larger values show increasing heterogeneity. A value greater than $50 \%$ may be considered significant heterogeneity.

\section{Assessment of reporting biases}

For future updates, to investigate whether this review is subject to publication bias, the authors will construct a funnel plot, if sufficient trials are included (at least 10). In the absence of bias, the plot should resemble a symmetrical inverted funnel (Sterne 2011). If there is asymmetry, the authors will consider publication bias and other reasons (such as location biases, true heterogeneity, high risk of bias of smaller trials, etc.) as a potential cause.

\section{Data synthesis}

If the authors consider any trials identified in the future to be clinically similar enough to combine (e.g. pulmonary exacerbation trials with different types of antibiotics, oral versus intravenous, different lengths of treatment), they will investigate statistical heterogeneity as outlined below. If there is no significant heterogeneity, they will calculate the pooled effect estimates using a fixed-effect model. If they identify significant heterogeneity $\left(I^{2}\right.$ greater than 50\%) (Higgins 2003), they will perform a randomeffects meta-analysis to address heterogeneity among trials.

\section{Subgroup analysis and investigation of heterogeneity}

In future updates, if there are at least 10 trials included in the review and if the authors find significant heterogeneity as defined above $\left(I^{2}\right.$ greater than 50\%) (Higgins 2003), they will explore the potential causes of this (i.e. different types of antimicrobial treatment such as oral, inhaled or intravenous; different participant populations etc.) and if possible, conduct subgroup analyses of the trials. For example, trial results may vary if different 
types of antibiotic treatments are used (e.g. oral, inhaled or intravenous) for the treatment of pulmonary infection in different settings, e.g. acute pulmonary exacerbation or as suppressive treatment. In addition, results may vary if one trial has more adult participants who can produce sputum (a more accurate sample with potentially more reliable culture results) and another trial has more pediatric participants where only throat swabs are used (a less reliable respiratory tract sample). Finally, there may be differences depending on whether antibiotics are used to treat a first-time infection (eradication) versus an established, chronic infection (over $50 \%$ of cultures positive in the previous 12 months).

\section{Sensitivity analysis}

If the authors are able to include at least 10 trials in future updates of the review, they will perform a sensitivity analysis to determine whether the conclusions are robust to decisions made during the review process such as the inclusion or exclusion of particular trials from a meta-analysis, imputing missing data or choice of a method for analysis. They will investigate whether changing which trials are included, based on their assessment of the risk of bias (including or excluding trials with any high risk of bias) or changing their chosen statistical model (i.e. random-effects model compared to a fixedeffect model) changes the results of the review. If the sensitivity analysis does not significantly change the results, it strengthens the confidence that can be placed in these results. The authors will present the results in an influence plot, as appropriate.

\section{Summary of findings table}

In accordance with current Cochrane guidance, we have included a summary of findings table for the comparison of biofilm testing versus standard testing (post hoc change at 2017 update). We have selected the following outcomes which we consider to be the most important to include.

1. $\mathrm{FEV}_{1}(\mathrm{~L})$

2. $\mathrm{FEV}_{1}$ (\% predicted)

3. Time to next exacerbation

4. Adverse events

5. Sputum density

6. Quality of life (CFQ-R)

We have used the GRADE approach to assess the quality of the evidence for each outcome based on the risk of bias within the trials, relevance to our population of interest (indirectness), unexplained heterogeneity or inconsistency, imprecision of the results or high risk of publication bias. We downgraded the evidence once if the risk was serious and twice if the risk was deemed to be very serious.

\section{RES U L T S}

\section{Description of studies}

\section{Results of the search}

Four trials (18 unique records) were identified in the search. Two trials (nine records) were excluded (Aaron 2005; Oermann 2010). Therefore, the search identified two trials (nine records) with data eligible for inclusion in the review (Moskowitz 2011; Yau 2014).

\section{Included studies}

\section{Methods}

Both included trials were multicenter, randomized, doubleblind controlled clinical trials prospectively assessing whether the use of biofilm antimicrobial susceptibility testing improved microbiological and clinical outcomes (Moskowitz 2011; Yau 2014). The earlier trial was run across seven CF centers in the USA (Moskowitz 2011) and the later trial was run across five CF centers in Canada (Yau 2014).

\section{Participants}

\section{Inclusion and exclusion criteria}

The earlier trial studied participants with CF who were stable and infected with $P$ aeruginosa (Moskowitz 2011), while the later trial enrolled participants with CF who were chronically infected with $P$ aeruginosa and experiencing a pulmonary exacerbation (Yau 2014).

In the earlier trial, participants were eligible for enrolment if they had a confirmed diagnosis of CF, were at least 14 years of age, could spontaneously produce sputum, were able to reliably perform pulmonary function tests, were chronically infected with $P$ aeruginosa, were clinically stable at the time of enrolment and provided written consent (Moskowitz 2011). Chronic infection with $P$ aeruginosa was defined as a history of persistent $P$ aeruginosa airway infection, defined as any combination of three or more sputum or bronchoalveolar lavage fluid cultures positive for $P$ aeruginosa during the 24 months prior to screening, subsequently amended to allow oropharyngeal cultures as evidence for persistent infection. The later trial had very similar inclusion criteria, except that there was no age restriction for enrolment and participants were experiencing a pulmonary exacerbation rather than being clinically stable (Yau 2014).

Participants were excluded from the Moskowitz trial if the $P$ aeruginosa sputum density was less than $10^{5}$ colony forming units (CFU)/g at screening, if they were infected with Burkholderia cepacia complex at screening or in the previous 24 months, if they were allergic to more than two classes of antibiotics, if they had received a lung transplantation or if they were pregnant (Moskowitz 2011). It is important to note that the participants had no oral or inhaled antibiotics within 14 days prior to screening and no treatment for an acute exacerbation or other administration of parenteral anti-pseudomonal antibiotics within two months prior to screening. In the Yau trial, additional exclusion criteria included being listed for lung transplantation and a decision by the treating physician to use antibiotics other than those prescribed by the principal investigator (VW) (Yau 2014).

\section{Enrolled participants}

Both trials enrolled 39 participants each (Moskowitz 2011; Yau 2014). In the Moskowitz trial, 20 were allocated to the biofilmtreated group and 19 to the conventionally-treated (control) group (Moskowitz 2011). In the Yau trial, although the same total number of participants were randomized, the trial presented data for more than one randomized exacerbation per participant; 24 participants were randomized to the biofilm-treated group (48 exacerbations) and 15 to the conventionally-treated (control) group (26 exacerbations) (Yau 2014). 
In the Moskowitz trial, the mean (SD) age in the biofilm group was 32 (9.3) years and in the control group was 28.2 (8.6) years (Moskowitz 2011). The participants were slightly younger in the Yau trial; the mean (range) age in the biofilm group was 29.4 (11.3 to 49.2) years and in the control group 22.6 (10.1 to 53.2) years (Yau 2014).

The gender split of participants was reported by both trials. In the Moskowitz trial, 25 participants were male (16 in the biofilm group and 9 in the control group) and 14 were female (four in the biofilm group and 10 in the control group) (Moskowitz 2011). Yau recruited 14 males (11 in the biofilm group and three in the control group) and 25 females ( 13 in the biofilm group and 12 in the control group) (Yau 2014).

In both trials the number of participants homozygous with the genotype delta F508 was 11 in the biofilm group and nine in the control group (Moskowitz 2011; Yau 2014).

Pancreatic insufficiency was also reported by both trials. Moskowitz stated that a total of 34 out of 39 participants were pancreatic insufficient (18 in the biofilm group and 16 in the control group) (Moskowitz 2011). Yau reported that 35 out of 39 participants were pancreatic insufficient ( 22 in the biofilm group and 13 in the control group) (Yau 2014).

Moskowitz reported the mean (SD) baseline $\mathrm{FEV}_{1} \%$ predicted in participants; in the biofilm group this was $62.2 \%$ (23.2) and in the control group was 64\% (28.2) (Moskowitz 2011). Baseline lung function was slightly lower in the Yau trial; the mean (range) baseline $\mathrm{FEV}_{1} \%$ predicted in the biofilm group was 53.3\% (26.8 to 83.9 ) and $60.6 \%$ (25.2 to 98.3) in the control group (Yau 2014).

\section{Interventions}

In the Moskowitz trial, clinically stable participants were randomized to receive a 14-day course of any two antibiotics (intravenous or oral) chosen on the basis of results from either conventional or biofilm antimicrobial susceptibility testing of their $P$ aeruginosa isolate cultured from the sputum obtained at the screening visit (Moskowitz 2011). In contrast, in the Yau trial, participants were randomized at the time of a pulmonary exacerbation requiring intravenous antibiotics. At that time, enrolled participants were randomized to receive a 14-day course of two intravenous antibiotics chosen by the primary investigator (VW) based on the results of either conventional or biofilm antimicrobial susceptibility testing of their $P$ aeruginosa isolate cultured from the most recently obtained sputum (Yau 2014).

\section{Outcomes}

The primary outcome for the Moskowitz trial was the microbiological response to antibiotic therapy, measured by the change in $P$ aeruginosa sputum density, calculated as logarith $m_{10}$ $\left(\log _{10}\right)$ of end-of-treatment density minus $\log _{10}$ of screening density in CFU/g (Moskowitz 2011). The Yau trial also had microbiological response as the primary outcome but this was determined as the proportion of exacerbations in the biofilm versus the conventional group in which $a \geq 3 \log _{10}$ drop in sputum density of $P$ aeruginosa in $\mathrm{CFU} / \mathrm{mL}$ was achieved from day 0 to day 14 of antibiotic treatment. The change in sputum bacterial density was also calculated in each group from day 0 to day 14 of antibiotic treatment and to the one-month follow up, an additional time point not included in the Moskowitz trial (Yau 2014).
The secondary outcome measure in the Moskowitz trial was pulmonary response, measured as change in $\mathrm{FEV}_{1}$ (liters) and calculated as end-of-treatment FEV ${ }_{1}$ minus the baseline FEV (Moskowitz 2011). Secondary outcomes in the Yau trial similarly included change in pulmonary function tests, measured by both FEV $_{1}$ and forced vital capacity (in liters and \% predicted), from day 0 to day 14 of antibiotic treatment to one-month follow-up (Yau 2014). Additional secondary outcomes in the Yau trial included change in CFQ-R respiratory scores, serum white blood cell count (WBC), C-reactive protein (CRP), erythrocyte sedimentation rate (ESR) and sputum IL-8 and neutrophil elastase measured for all pulmonary exacerbations in both groups at day 0 , day 14 of antibiotic therapy and at the one-month follow up visit.

\section{Excluded studies}

Two trials (nine records) were excluded because they did not concern the topic of this review; one looked at combination antibiotic susceptibility testing (Aaron 2005); and the second one looked at antibiotic susceptibility of $P$ aeruginosa isolates after repeated courses of inhaled aztreonam lysine (Oermann 2010).

\section{Risk of bias in included studies}

The overall risk of bias was minimal in the included trials (Moskowitz 2011; Yau 2014).

\section{Allocation}

\section{Sequence generation}

In the Moskowitz trial, participants were assigned to treatment groups using a block randomization procedure, stratified by trial site, using computer-generated random numbers. Randomization was done similarly in the Yau study, by computer-generated random numbers table, stratified by trial site. The allocation of the intervention was therefore deemed to have a low risk of bias in both trials (Moskowitz 2011; Yau 2014).

\section{Concealment of allocation}

In the Moskowitz trial, randomization assignments were placed in numbered, sealed envelopes which were opened sequentially at the time of randomization by the statistician or their designated representative. The remaining research staff, the participants and their caregivers were unaware of the allocation. In the Yau trial, the method of selection was blinded to all participants, treating team and trial personnel except for the co-principal investigator who performed the randomization. The concealment of the allocation was therefore deemed to have a low risk of bias in both trials (Moskowitz 2011; Yau 2014).

\section{Blinding}

In both trials, the person responsible for participant care, the participant and the outcome assessor were aware of the antibiotic choices but were blinded to the testing method (biofilm or conventional) upon which this choice was based. Therefore, there was a low risk of performance and detection bias in both studies (Moskowitz 2011; Yau 2014).

\section{Incomplete outcome data}

In the Moskowitz trial, 39 participants were randomized - 20 to the biofilm-treated group and 19 to the conventionally-treated (control) group. One participant was randomized but withdrawn 
prior to treatment and subsequently re-randomized and treated. Of the 20 participants who were randomized to the biofilm group, two withdrew prior to treatment; of the 19 randomized to the control group, three withdrew prior to treatment. One participant from each group discontinued treatment due to adverse events. In the modified intent-to-treat analysis, 18 of the 20 participants randomized to the biofilm group and 16 of the 19 participants randomized to the control group were analyzed for FEV 1 data; 17 of the 20 in the biofilm group and 14 of the 19 in the control group were analyzed for sputum density data. Thus, less than $15 \%$ of the participants randomized in the trial were excluded from the final analysis for lung function data (Moskowitz 2011). In the Yau trial, of 41 participants randomized, 39 were analyzed. A total of two participants $(5 \%)$ were excluded (one from each group) with no data available for either. One participant from the conventional group was excluded due to loss to follow up and one participant was excluded from the biofilm group because there was no growth of $P$ aeruginosa on Day 1 of treatment (Yau 2014). The risk of attrition bias for both trials was therefore deemed to be low.

\section{Selective reporting}

For the Moskowitz trial, the planned outcome measures published in the original trial protocol on www.clinicaltrials.gov (NCT00153634) were almost the same as those reported in the final manuscript. We believe that any hospitalization data would likely be collected for safety issues and do not regard the lack of reporting for this outcome to constitute a risk of bias. However, with regards to lung function reporting, the trial only reports results for FEV ${ }_{1}$, although we would expect the measurements FVC and $\mathrm{FEF}_{25-75 \%}$ to have been undertaken as part of the standard set of lung function tests at clinic visits. As we can not be certain that these tests were definitely undertaken, we judge there to be an unclear risk of bias with regards to selective reporting (Moskowitz 2011). For the Yau trial, all the outcomes listed in the protocol accessed from www.clinicaltrials.gov (NCT00786513) were fully reported in the paper and the online supplementary materials. Therefore the Yau trial was deemed to have a low risk of reporting bias (Yau 2014).

\section{Other potential sources of bias}

There were no other potential sources of bias identified.

\section{Effects of interventions}

See: Summary of findings for the main comparison

\section{Primary outcomes}

\section{Lung function}

a. FEV

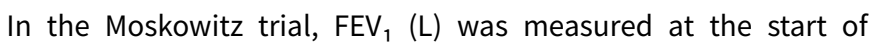
treatment (Day 0) and follow up (Day 14) in 18 participants in the biofilm group and 16 participants in the control group. In the Yau trial, FEV 1 measurements (in both \% predicted and $\mathrm{L}$ ) were obtained at Day 0, Day 7, Day 14 of antibiotic treatment and at the onemonth follow up for both groups. We were therefore only able to combine data from the two trials for the FEV ${ }_{1}(\mathrm{~L})$, change from start of treatment to Day 14 which produced a combined reported MD between groups of $0.04 \mathrm{~L}(95 \% \mathrm{Cl}-0.08$ to 0.16$)$ (high-quality evidence) (Analysis 1.1). For the Yau trial, we also analyzed data on FEV $_{1}$ for the change from start of treatment to Day 14 measured in $\%$ predicted, MD $-2.47 \%(95 \% \mathrm{Cl}-9.29$ to 4.34$)$ (Analysis 1.2). The
GRADE quality of evidence was deemed to be moderate for $\mathrm{FEV}_{1} \%$ predicted due to small numbers from one trial.

\section{b. FVC}

Data were not reported for this outcome for the Moskowitz trial (Moskowitz 2011). For the Yau trial, FVC measurements were obtained at Day 0, Day 7, Day 14 of antibiotic treatment and at the one-month follow up for both groups (Yau 2014). The change in FVC $\%$ predicted from start of treatment to Day 14 was reported for both groups, MD -2.27 (95\% Cl-9.06 to 4.51) (Analysis 1.3); when reported in liters, our analysis showed MD $-0.03 \mathrm{~L}(95 \%-0.32$ to 0.26$)$ (Analysis 1.4).

\section{c. FEF $_{25-75}$}

Data were not reported for this outcome by either trial (Moskowitz 2011; Yau 2014).

\section{Pulmonary exacerbations}

For the Moskowitz trial, there were no pulmonary exacerbations in either group during the trial period (Moskowitz 2011). Given the design of the Yau trial which re-randomized participants after they had experienced an exacerbation, a calculation of the number of exacerbations by treatment group was not possible (Yau 2014). However, the time to subsequent pulmonary exacerbation requiring intravenous antibiotics was calculated for each randomized exacerbation in both the conventional and biofilm groups. The median time to subsequent exacerbation was 185 days in the conventional group and 162 days in the biofilm group; the difference in the survival curves was not significant ( $P=0.8$, Mantel-Cox test). The HR for subsequent exacerbation demonstrated no significant difference between groups 0.54 (95\% $\mathrm{Cl} 0.25$ to 1.16) (Analysis 1.5). In addition, the RR between groups for developing an exacerbation during the trial period was not significant, RR $0.83(95 \% \mathrm{Cl} 0.57$ to 1.22$)$ (moderate-quality evidence) (Analysis 1.6).

\section{Adverse events}

a. mild

In the Moskowitz trial, 12 participants from each group experienced at least one mild adverse event such as diarrhoea, fatigue, headache or oral candidiasis, which did not require any treatment change (Moskowitz 2011). In the Yau trial, there were nine episodes of mild adverse events in the conventional group and seven episodes of mild adverse events in the biofilm group that did not require discontinuation of treatment (Yau 2014). The combined analysis showed a RR of 0.70 ( $95 \% \mathrm{Cl} 0.48$ to 1.04$)$ (Analysis 1.7).

\section{b. moderate}

In the Moskowitz trial, one participant from each group experienced a moderate adverse event that led to discontinuation of treatment (Moskowitz 2011). In the Yau trial, there were four pulmonary exacerbations (three in the conventional group and one in the biofilm group) in which there were moderate adverse events leading to discontinuation of the antibiotic (Yau 2014). The combined RR was $0.36(95 \% \mathrm{Cl} 0.07$ to 1.77$)$ (moderate-quality evidence) (Analysis 1.7).

\section{c. severe}

There were no serious adverse events reported (such as death or hospitalization) in either trial (Analysis 1.7). 


\section{Secondary outcomes}

\section{Sputum bacterial density}

In the Moskowitz trial, 17 participants in the biofilm group and 14 participants in the control group had $P$ aeruginosa sputum density measurements taken at baseline (Day 0 ) and at follow-up (Day 14) (Moskowitz 2011). In the Yau trial, sputum $P$ aeruginosa density measured in $\log _{10} \mathrm{CFU} / \mathrm{mL}$ was reported for Day 0, Day 14 of antibiotic treatment and at the one-month follow up for all exacerbations in both groups (Yau 2014). We were therefore able to combine data from both studies for the change in $P$ aeruginosa sputum density from start of treatment to Day 14 and report the MD between groups of $0.80(95 \% \mathrm{Cl}-0.59$ to 2.18$)$ (high-quality evidence) (Analysis 1.8).

\section{QOL}

Data were not collected for QoL measures in the Moskowitz trial (Moskowitz 2011). In the Yau trial, respiratory symptom scores based on the CFQ-R questionnaire were obtained at Day 0, Day 14 of antibiotic treatment and at the one-month follow up for both groups (Yau 2014). There was a significant difference between groups in the change in CFQ-R scores from start of treatment, MD $-15.04(95 \% \mathrm{Cl}-28.38$ to -1.71$)$ at Day 14 and $-17.03(95 \% \mathrm{Cl}-30.13$ to -3.92) at one month (moderate-quality evidence) (Analysis 1.9).

\section{Mortality}

There were no deaths reported in either group during either trial (Moskowitz 2011; Yau 2014).

\section{Nutritional parameters}

Data were not collected for this outcome for either trial (Moskowitz 2011; Yau 2014).

\section{Number of hospitalizations}

Data were not collected for this outcome for either trial (Moskowitz 2011; Yau 2014).

\section{Use of oral antibiotics}

Data were not collected for this outcome for either trial (Moskowitz 2011; Yau 2014).

\section{DISCUSSION}

\section{Summary of main results}

The trials by Moskowitz and Yau demonstrated that the use of biofilm antimicrobial susceptibility testing to guide antibiotic treatment of chronic $P$ aeruginosa infections in people with CF did not result in a greater decrease in sputum bacterial density or improved lung function (Moskowitz 2011; Yau 2014). The major strength of the Moskowitz trial was its clinical methodology; it included participants enrolled from seven CF centers in the USA and both the intervention and control groups had similar baseline characteristics. Similarly, the Yau trial was a multicenter (five Canadian sites) randomized controlled trial with an overall low risk of bias.

\section{Overall completeness and applicability of evidence}

Both included trials studied biofilm antimicrobial susceptibility testing in both children and adults with CF, under conditions of clinical stability as well as during pulmonary exacerbations (Moskowitz 2011; Yau 2014). Both trials used similar experimental methodologies, growing $P$ aeruginosa biofilms on plastic pegs and then exposing them to antibiotics in 96 well plates for 24 hours and measuring inhibition of growth. The method by which antibiotics were chosen, however, was slightly different between trials. In the Moskowitz trial, antibiotics were chosen based on the highest ratio of the maximum achievable serum concentration over the inhibitory concentration whereas in the Yau trial, susceptible drugs were chosen according to breakpoints based on systemically achievable antibiotic concentrations as defined by the Clinical Laboratory Standards Institute (CLSI 2012). In both instances, though, antibiotic treatment was administered systemically (either intravenously or orally) and antibiotics choices based on the lower drug concentrations achievable in serum. In the end, although preliminary data showed that antibiotic choices do differ based on biofilm versus conventional antimicrobial susceptibility testing (Moskowitz 2005), the antibiotic regimens in the treatment and control arms were very similar in both studies. This may be due to an inability to identify more effective antibiotics against biofilm-grown organisms at such low drug concentrations. In addition, the similarity between treatment regimens may also have been a result of a limited number of antimicrobial classes with anti-pseudomonal activity. The higher intrapulmonary concentrations achievable through aerosolization of antibiotics, such as tobramycin, may be more effective against bacterial biofilms, but whether biofilm susceptibility testing using these higher drug concentrations results in improved clinical outcomes remains to be determined (Chmiel 2014). It is difficult for an in vitro system to replicate all the complexities of the biofilm environment in the CF lung and there is much that we do not understand about how antibiotics work to make people with CF better. In addition to their microbiological effect, they may have anti-inflammatory effects that are not routinely measured (Wagner 2005).

\section{Quality of the evidence}

There was little risk of bias in either trial as the randomization of participants was appropriately concealed and participants, caregivers and investigators were blinded to the assignment. Follow up was also adequate as outcomes measures were obtained in the majority of randomized participants. In addition to the methods, another strength of the Moskowitz trial was the systematic way in which antibiotics were chosen in each group (Moskowitz 2011). The investigators designed an algorithm to calculate the conventional minimum inhibitory quotient and the biofilm minimum inhibitory quotient of each drug based on the achievable serum concentration divided by conventional or biofilm minimum inhibitory concentrations, respectively. Antibiotics were then chosen based on the highest quotient of each drug in each class of antibiotics. This algorithm ensured a degree of objectivity and reproducibility in the choosing of antibiotics to treat $P$ aeruginosa infections in individuals with $\mathrm{CF}$, which can often be a subjective process influenced by physician preferences and various patient factors. Although the algorithm was complex, the authors designed a publicly available computer-based model that could be used by any treating physician, rendering the results more generalizable (Moskowitz 2004). The Yau trial did not choose antibiotics according to inhibitory quotients, but did follow a welldescribed algorithm based on a previously published hierarchy of antibiotics (Moskowitz 2005). In addition, all antibiotic regimens 
for both arms of the trial were chosen in a blinded fashion by the principal investigator, eliminating any bias introduced by multiple prescribers (Aaron 2005). Finally, although biofilm antimicrobial susceptibility testing was not shown to be superior to conventional testing, it was at least as safe in both trials, with an equal number of adverse events in each group, and as effective, with comparable decreases in sputum density and improvements in lung function, as conventional testing.

The quality of the evidence provided by the two trials, and assessed using the GRADE criteria, was deemed to be high for two outcomes and moderate for the remaining four outcomes presented in Summary of findings for the main comparison. The most common reason for downgrading the evidence was due to imprecision from small sample sizes, where only one trial could be included in the analysis. For adverse events, the quality of the evidence was downgraded due to imprecision again but due to low event rates.

\section{Potential biases in the review process}

There were no perceived biases in this review process.

\section{AUTHORS' CONCLUSIONS}

\section{Implications for practice}

The current evidence, limited to two trials, shows that there is insufficient evidence to recommend choosing antibiotics based on biofilm antimicrobial susceptibility testing rather than conventional antimicrobial susceptibility testing in the treatment of Pseudomonas aeruginosa pulmonary infections in people with cystic fibrosis (CF).

\section{Implications for research}

Although in vitro biofilm antimicrobial susceptibility systems cannot currently predict better antibiotic choices for the treatment of pulmonary infections in individuals with CF, biofilms are still relevant given the known growth conditions of bacteria in CF lung. Testing antimicrobials against bacterial biofilms in the laboratory may be more appropriate in the development of newer, more effective formulations of drugs, able to penetrate CF sputum and bacterial structures, which can then be tested in clinical trials.

\section{ACKN OWLEDGEMENTS}

The authors acknowledge the kind assistance of Dr Samuel Moskowitz and Dr Julia Emerson who provided us with the details of the allocation assignments and additional outcome measures for their trial.

This project was supported by the National Institute for Health Research, via Cochrane Infrastructure funding to the Cochrane Cystic Fibrosis and Genetic Disorders Group. The views and opinions expressed therein are those of the authors and do not necessarily reflect those of the Systematic Reviews Programme, NIHR, NHS or the Department of Health. 
R E F E R E N C E S

\section{References to studies included in this review}

Moskowitz 2011 \{published data only\}

Moskowitz SM, Emerson JC, McNamara S, Shell RD, Orenstein DM, Rosenbluth $D$, et al. Randomized trial of biofilm testing to select antibiotics for cystic fibrosis airway infection. Pediatric Pulmonology 2011;46(2):184-92. [CFGD Register: PI245]

\section{Yau 2014 \{published data only\}}

Ratjen F, Stanojevic S, Sonneveld N, Grasemann H, Yau Y, Tullis E, et al. Predictors of response to antibiotic treatment of pulmonary exacerbations in cystic fibrosis patients [abstract]. Pediatric Pulmonology 2014;49 Suppl 38:355, Abstract no: 384. [CENTRAL: 1012525; CFGD Register: PI244c ; CRS: 5500131000000179]

Waters V, Ratjen F, Tullis E, Corey M, Matukas L, Leahy R, et al. Randomized double blind controlled trials of the use of a biofilm antimicrobial susceptibility assay to guide antibiotic therapy in chronic pseudomonas aeruginosa infected cystic fibrosis patients [abstract]. Pediatric Pulmonology 2010;45(Suppl 33):339, Abstract no: 311. [CFGD Register: PI244a]

Waters V, Yau Y. Use of a biofilm antimicrobial susceptibility assay to guide antibiotic therapy. http://clinicaltrials.gov/ show/NCT00786513 (accessed 11 March 2015). [CFGD Register: $\mathrm{PI} 244 \mathrm{~g}]$

Waters VJ, Ratjen F, Tullis E, Wilcox PG, Freitag A, Chilvers M, et al. Randomized controlled trial of biofilm antimicrobial susceptibility testing in pulmonary exacerbations in cystic fibrosis patients with chronic pseudomonas aeruginosa infection [abstract]. Pediatric Pulmonology 2014;49 Suppl 38:319, Abstract no: 287. [CFGD Register: PI244b ; CRS: 5500131000000178]

Waters VJ, Stanojevic S, Sonneveld N, Klingel M, Grasemann H, Yau YC, et al. Factors associated with response to treatment of pulmonary exacerbations in cystic fibrosis patients. Journal of Cystic Fibrosis: Official Journal of the European Cystic Fibrosis Society 2015;14(6):755-62. [CFGD Register: PI244h; CRS: 5500135000001435; PUBMED: 25690407]

Yau YCW, Ratjen F, Tullis E, Wilcox P, Freitag A, Chilvers M, et al. Online supplement to "Randomized controlled trial of biofilm antimicrobial susceptibility testing in cystic fibrosis patients". Journal of Cystic Fibrosis 2015;14:1-13 online. [CFGD Register: $\mathrm{PI} 244 \mathrm{e}]$

Yau YCW, Ratjen F, Tullis E, Wilcox P, Freitag A, Chilvers M, et al. Online supplementary tables from "Randomized controlled trial of biofilm antimicrobial susceptibility testing in cystic fibrosis patients". Journal of Cystic Fibrosis 2015;14:1-4 online. [CFGD Register: PI244f]

* Yau YCW, Ratjen F, Tullis E, Wilcox P, Freitag A, Chilvers M, et al. Randomized controlled trial of biofilm antimicrobial susceptibility testing in cystic fibrosis patients. Journal of Cystic Fibrosis 2015;14:262-6. [CENTRAL: 1015278; CFGD Register: PI244d ; CRS: 5500131000000261]

\section{References to studies excluded from this review}

Aaron 2005 \{published data only\}

Aaron S. Clinical evidence for combination antibiotic susceptibility testing (synergy testing) [abstract]. Pediatric Pulmonology 2008;43(Suppl 31):157. [CFGD Register: PI198c]

Aaron S, Vandemheen K, Ferris W, Tullis E, Haase D, Berthiaume $Y$, et al. Treatment of CF exacerbations based on multiple combination antibiotic susceptibility testing-a randomized, double-blind, controlled clinical trial [abstract]. Pediatric Pulmonology 2005;40(Suppl 28):304. [CFGD Register: PI198a]

* Aaron SD, Vandemheen KL, Ferris W, Fergusson D, Tullis E, Haase D, et al. Combination antibiotic susceptibility testing to treat exacerbations of cystic fibrosis associated with multiresistant bacteria: a randomised, double-blind, controlled clinical trial. Lancet 2005;366(9484):463-71. [CFGD Register: PI198b]

\section{Oermann 2010 \{published data only\}}

Oermann CM, McCoy KS, Retsch-Bogart GZ, Gibson R, McKevitt M, Montgomery B. Antibiotic susceptibility in Pseudomonas Aeruginosa (PA) isolates following repeated exposure to aztreonam for inhalation solution (AZLI) in patients with cystic fibrosis [abstract]. Pediatric Pulmonology 2009;44(Suppl 32):309, Abstract no: 278. [CFGD Register: PI220a]

Oermann CM, McCoy KS, Retsch-Bogart GZ, Gibson R, McKevitt M, Montgomery B. Effect of repeated exposure to aztreonam for inhalation solution (AZLI) therapy on cystic fibrosis respiratory pathogens [abstract]. Pediatric Pulmonology 2009;44(Suppl 32):335, Abstract no: 353. [CFGD Register: $\mathrm{PI} 220 \mathrm{~d}]$

Oermann CM, McCoy KS, Retsch-Bogart GZ, Gibson RL, Montgomery AB. Effect of multiple courses of Aztreonam Lysine for inhalation (AZLI) on FEV1 and weight in patients with cystic fibrosis (CF) and Pseudomonas aeruginosa (PA): analysis of 18 month data from CP-Al-006 [abstract]. Journal of Cystic Fibrosis 2009;8(Suppl 2):S28, Abstract no: 107. [CFGD Register: PI220c]

Oermann CM, McCoy KS, Retsch-Bogart GZ, Gibson RL, Quittner AL, Montgomery AB. Adherence over multiple courses of Aztreonam for inhalation (AZLI): effect on diseaserelated endpoints in patients with cystic fibrosis (CF) and Pseudomonas aeruginosa (PA) [abstract]. Journal of Cystic Fibrosis 2009;8(Suppl 2):S28, Abstract no: 109. [CFGD Register: $\mathrm{PI} 220 \mathrm{~b}]$

* Oermann CM, Retsch-Bogart GZ, Quittner AL, Gibson RL, McCoy KS, Montgomery AB, et al. An 18-month study of the safety and efficacy of repeated courses of inhaled aztreonam lysine in cystic fibrosis. Pediatric Pulmonology 2010;45(11):1121-34. [CFGD Register: PI220e]

Quittner AL, Henig NR, Lewis S, Derchak PA, McCoy KS, Oermann CM, et al. Effects of chronic intermittent aztreonam for inhalation solution (AZLI) on health-related quality of life 
(HRQOL) in persons with cystic fibrosis (CF) and P. aeruginosa [abstract]. Pediatric Pulmonology 2011;46 Suppl 34:299, Abstract no: 240. [CENTRAL: 867260; CFGD Register: PI220f // PI213j; CRS: 5500100000011261]

\section{Additional references}

\section{Bjarnsholt 2009}

Bjarnsholt T, Jensen PØ, Fiandaca MJ, Pedersen J, Hansen CR, Andersen CB, et al. Pseudomonas aeruginosa biofilms in the respiratory tract of cystic fibrosis patients. Pediatric Pulmonology 2009;44(6):547-58.

\section{Burns 2001}

Burns JL, Gibson RL, McNamara S, Yim D, Emerson J, Rosenfeld M, et al. Longitudinal assessment of Pseudomonas aeruginosa in young children with cystic fibrosis. Journal of Infectious Diseases 2001;183(3):444-52.

\section{Ceri 1999}

Ceri H, Olson ME, Stremick C, Read RR, Morck D, Buret A. The Calgary Biofilm Device: new technology for rapid determination of antibiotic susceptibilities of bacterial biofilms. Journal of Clinical Microbiology 1999;37(6):1771-6.

\section{Chmiel 2014}

Chmiel JF, Aksamit TR, Chotirmall SH, Dasenbrook EC, Elborn JS, LiPuma JJ, Ranganathan SC, Waters VJ, Ratjen FA. Antibiotic Management of Lung Infections in Cystic Fibrosis: Part I. The Microbiome, MRSA, Gram-Negative Bacteria, and Multiple Infections. Ann Am Thorac Soc 2014 Sep;11(7):1120-9.

\section{CLSI 2012}

Clinical and Laboratory Standards Institute. Performance standards for antimicrobial susceptibility testing. Vol. Twentysecond informational supplement M100-S22, Wayne, PA: Clinical \& Laboratory Standards Institute, 2012. [ISBN-10: 1562388983]

\section{Donner 2001}

Donner A, Piaggio G, Villar J. Statistical methods for the metaanalysis of cluster randomized trials. Statistical Methods in Medical Research 2001;10(5):325-38.

\section{Drenkard 2002}

Drenkard E, Ausubel FM. Pseudomonas biofilm formation and antibiotic resistance are linked to phenotypic variation. Nature 2002;416(6882):740-3.

\section{Elbourne 2002}

Elbourne DR, Altman DG, Higgins JPT, Curtin F, Worthington HV, Vail A. Meta-analyses involving cross-over trials: methodological issues. International Journal of Epidemiology 2002;31(1):140-9.

\section{Foweraker 2005}

Foweraker JE, Laughton CR, Brown DF, Bilton D. Phenotypic variability of Pseudomonas aeruginosa in sputa from patients with acute infective exacerbation of cystic fibrosis and its impact on the validity of antimicrobial susceptibility testing. Journal of Antimicrobial Chemotherapy 2005;55(6):921-7.

\section{Frederiksen 1996}

Frederiksen B, Lanng S, Koch C, Hoiby N. Improved survival in the Danish center-treated cystic fibrosis patients: results of aggressive treatment. Pediatric Pulmonology 1996;21(3):153-8.

\section{Fuchs 1994}

Fuchs HJ, Borowitz DS, Christiansen DH, Morris EM, Nash ML, Ramsey BW, et al. Effect of aerosolized recombinant human DNase on exacerbations of respiratory symptoms and on pulmonary function in patients with cystic fibrosis. The Pulmozyme Study Group. New England Journal of Medicine 1994;331(10):637-42.

\section{Gee 2000}

Gee L, Abbott J, Conway S, Etherington C, Webb A. Development of a disease specific health related quality of life measure for adults and adolescents with cystic fibrosis. Thorax 2000;55(11):946-54.

\section{Gibson 2003}

Gibson RL, Burns JL. Pathophysiology and management of pulmonary infections in cystic fibrosis. American Journal of Respiratory and Critical Care Medicine 2003;168(8):918-51.

\section{Gilligan 2006}

Gilligan PH. Is there value in susceptibility testing of Pseudomonas aeruginosa causing chronic infection in patients with cystic fibrosis?. Expert Review of Anti-infective Therapy 2006;4(5):711-5.

\section{Henry 1992}

Henry RL, Mellis CM, Petrovic L. Mucoid Pseudomonas aeruginosa is a marker of poor survival in cystic fibrosis. Pediatric Pulmonology. 1992;12(3):158-61.

\section{Higgins 2003}

Higgins JPT, Thompson SG, Deeks JJ, Altman DG. Measuring inconsistency in meta-analyses. BMJ 2003;327(7414):557-60.

\section{Higgins 2011a}

Higgins JPT, Altman DG. Chapter 8: Assessing risk of bias in included studies. In: Higgins JPT, Green S (editors). Cochrane Handbook of Systematic Reviews of Interventions. Version 5.1 [updated March 2011]. The Cochrane Collaboration, 2011. Available from www.cochrane-handbook.org.

\section{Higgins 2011b}

Deeks JJ, Higgins JPT, Altman DG. Chapter 9: Analysing data and undertaking meta-analyses. In: Higgins JPT, Green S (editors). Cochrane Handbook of Systematic Reviews of Interventions. Version 5.1 [updated March 2011]. The Cochrane Collaboration, 2011. Available from www.cochrane-handbook.org.

\section{Jorgensen 2009}

Jorgensen JH, Ferraro MJ. Antimicrobial susceptibility testing: a review of general principles and contemporary practices. Clinical Infectious Diseases 2009;49(11):1749-55.

\section{Kosorok 2001}

Kosorok MR, Zeng L, West SE, Rock MJ, Splaingard ML, Laxova A, et al. Acceleration of lung disease in children with cystic 
fibrosis after Pseudomonas aeruginosa acquisition. Pediatric Pulmonology 2001;32(4):277-87.

\section{MacGowan 2008}

MacGowan AP, BSAC Working Parties on Resistance Surveillance. Clinical implications of antimicrobial resistance for therapy. Journal of Antimicrobial Chemotherapy 2008;62(Suppl 2):ii105-14.

\section{Moskowitz 2004}

Moskowitz SM, Foster JM, Emerson J, Burns JL. Clinically feasible biofilm susceptibility assay for isolates of Pseudomonas aeruginosa from patients with cystic fibrosis. Journal of Clinical Microbiology 2004;42(5):1915-22.

\section{Moskowitz 2005}

Moskowitz SM, Foster JM, Emerson JC, Gibson RL, Burns JL. Use of Pseudomonas biofilm susceptibilities to assign simulated antibiotic regimens for cystic fibrosis airway infection. Journal of Antimicrobial Chemotherapy 2005;56(5):879-86.

\section{Murray 2007}

Murray TS, Egan M, Kazmierczak BI. Pseudomonas aeruginosa chronic colonization in cystic fibrosis patients. Current Opinion in Pediatrics 2007;19(1):83-8.

\section{Pamukcu 1995}

Pamukcu A, Bush A, Buchdahl R. Effects of pseudomonas aeruginosa colonization on lung function and anthropometric variables in children with cystic fibrosis. Pediatric Pulmonology 1995;19(1):10-5.

\section{Parmar 1998}

Parmar MK, Torri V, Stewart L. Extracting summary statistics to perform meta-analyses of the published literature for survival endpoints. Statistics in Medicine 1998;17(24):2815-34.

\section{Prince 2002}

Prince AS. Biofilms, antimicrobial resistance, and airway infection. New England Journal of Medicine 2002;347(14):1110-1.

\section{Quittner 2009}

Quittner AL, Modi AC, Wainwright C, Otto K, Kirihara J, Montgomery AB. Determination of the minimal clinically important difference scores for the Cystic Fibrosis Questionnaire-Revised respiratory symptom scale in two populations of patients with cystic fibrosis and chronic Pseudomonas aeruginosa airway infection. Chest 2009;135(6):1610-8.

\section{Ramsey 1996}

Ramsey BW. Management of pulmonary disease in patients with cystic fibrosis. New England Journal of Medicine 1996;335(3):179-88.

\section{CHARACTERISTICS OF STUDIES}

Characteristics of included studies [ordered by study ID]

\section{Singh 2000}

Singh PK, Schaefer AL, Parsek MR, Moninger TO, Welsh MJ, Greenberg EP. Quorum-sensing signals indicate that cystic fibrosis lungs are infected with bacterial biofilms. Nature 2000;407(6805):762-4.

\section{Smith 2003}

Smith AL, Fiel SB, Mayer-Hamblett N, Ramsey B, Burns JL. Susceptibility testing of Pseudomonas aeruginosa isolates and clinical response to parenteral antibiotic administration: lack of association in cystic fibrosis. Chest 2003;123(5):1495-502.

\section{Sterne 2011}

Sterne JAC, Egger M, Moher D on behalf of the Cochrane Bias Methods Group. Chapter 10: Addressing reporting biases. In: Higgins JPT, Green S (editors). Cochrane Handbook of Systematic Reviews of Interventions. Version 5.1 [updated March 2011]. The Cochrane Collaboration, 2011. Available from www.cochrane-handbook.org.

\section{Tielen 2010}

Schobert M, Tielen P. Contribution of oxygen-limiting conditions to persistent infection of Pseudomonas aeruginosa. Future Microbiology 2010;5(4):603-21.

\section{Wagner 2005}

Wagner T, Soong G, Sokol S, Saiman L, Prince A. Effects of azithromycin on clinical isolates of Pseudomonas aeruginosa from cystic fibrosis patients. Chest 2005;128(2):912-9.

\section{Waters 2008}

Waters V, Ratjen F. Combination antimicrobial susceptibility testing for acute exacerbations in chronic infection of Pseudomonas aeruginosa in cystic fibrosis. Cochrane Database of Systematic Reviews 2008, Issue 3. [DOI: 10.1002/14651858.CD006961.pub2]

\section{References to other published versions of this review Waters 2012}

Waters V, Ratjen F. Standard versus biofilm antimicrobial susceptibility testing to guide antibiotic therapy in cystic fibrosis. Cochrane Database of Systematic Reviews 2012, Issue 11. [DOI: 10.1002/14651858.CD009528.pub2]

\section{Waters 2015}

Waters V, Ratjen F. Standard versus biofilm antimicrobial susceptibility testing to guide antibiotic therapy in cystic fibrosis. Cochrane Database of Systematic Reviews 2015, Issue 3. [DOI: 10.1002/14651858.CD009528.pub3]

* Indicates the major publication for the study 
Moskowitz 2011

Randomized, double-blind controlled clinical trial.
Multicenter: 7 centers in USA.
$\begin{aligned} & \text { Participants randomized on the basis of results from either conventional or biofilm antimicrobial sus- } \\ & \text { ceptibility testing of their P aeruginosa isolate cultured from the sputum obtained at the screening vis- } \\ & \text { it. }\end{aligned}$

Participants 39 participants with CF: biofilm-treated group $(n=20)$ and conventionally-treated $($ control) group $(n=$ 19).

Mean (SD) age: biofilm group 32 (9.3) years; control group 28.2 (8.6) years.

Gender: biofilm group, 16 males and 4 females; control group, 9 males and 10 females.

Genotype delta F508 homozygous: biofilm group $n=11$; control group $n=9$.

Pancreatic insufficiency: biofilm group $n=18$; control group $n=16$.

Mean (SD) baseline FEV 1 \% predicted: biofilm group 62.2\% (23.2); control group 64\% (28.2).

Inclusion criteria: confirmed diagnosis of CF; 14 years of age or older; could spontaneously produce sputum; able to perform pulmonary function tests; chronically infected with $P$ aeruginosa; clinically stable at the time of enrolment; provided written consent.

Exclusion criteria: sputum P aeruginosa density was $<10^{5} \mathrm{CFU} / \mathrm{g}$ at screening; infected with $\mathrm{BCC}$ at screening or in the previous 24 months; allergic to more than 2 classes of antibiotics; received a lung transplantation; pregnant.

Interventions

A 14-day course of any 2 antibiotics (IV or oral) chosen on the basis of results from either conventional or biofilm antimicrobial susceptibility testing of their P aeruginosa isolate cultured from the sputum obtained at the screening visit.

Primary outcome: microbiological response to antibiotic therapy, measured by the change in $P$ aerug-
inosa sputum density, calculated as logarithm
screening density in CFU/g.

Secondary outcomes: pulmonary response, measured as change in $\mathrm{FEV}_{1} \mathrm{~L}$, calculated as end-of-treatment FEV 1 L minus the baseline $\mathrm{FEV}_{1} \mathrm{~L}$.

\section{Notes}

\section{Risk of bias}

\begin{tabular}{lll}
\hline Bias & Authors' judgement & Support for judgement \\
\hline $\begin{array}{l}\text { Random sequence genera- } \\
\text { tion (selection bias) }\end{array}$ & Low risk & $\begin{array}{l}\text { Participants assigned to treatment groups using a block randomization proce- } \\
\text { dure, stratified by trial site, using computer-generated random numbers. }\end{array}$ \\
\hline $\begin{array}{l}\text { Allocation concealment } \\
\text { (selection bias) }\end{array}$ & Low risk & $\begin{array}{l}\text { Randomization assignments placed in numbered sealed envelopes which } \\
\text { were opened sequentially at the time of randomization by the statistician or } \\
\text { their designated representative. The remaining research staff, the participants } \\
\text { and their caregivers were unaware of the allocation. }\end{array}$
\end{tabular}

Blinding of participants Low risk and personnel (performance bias)

All outcomes
The person responsible for participant care and the participant were aware of the antibiotic choices but were blinded to the testing method (biofilm or conventional) upon which this choice was based. 
Moskowitz 2011 (Continued)

Blinding of outcome as- Low risk The outcome assessor was aware of the antibiotic choices but was blinded sessment (detection bias) to the testing method (biofilm or conventional) upon which this choice was All outcomes based.

Incomplete outcome data Low risk (attrition bias)

All outcomes
39 participants randomized ( 20 to the biofilm-treated group, 19 to the conventionally-treated (control) group).

1 participant randomized, but withdrawn prior to treatment and subsequently re-randomized and treated.

Biofilm group: 2 withdrew prior to treatment; 1 discontinued treatment due to adverse events.

Control group: 3 withdrew prior to treatment. 1 discontinued treatment due to adverse events.

In the modified intent-to-treat analysis, 18 of the 20 participants in the biofilm group and 16 of the 19 participants in the control group were analyzed. Therefore, $\leq 15 \%$ of the participants randomized in the trial were excluded from the final analysis.

Selective reporting (re- Unclear risk
porting bias)
Trial outcomes published in the original trial protocol on www.clinicaltrials.gov (NCT00153634) were almost the same as the ones reported in the final manuscript. Hospitalization data would likely be collected for safety issues and so the lack of reporting for this outcome is not a risk of bias. However, for lung function, the trial only reports results for $\mathrm{FEV}_{1}$, although we would expect $\mathrm{FVC}$ and $\mathrm{FEF}_{25-75 \%}$ to have been undertaken as part of the standard set of lung function tests at clinic visits, hence unclear risk.

Other bias Low risk No other potential sources of bias identified.

Yau 2014

Rethods
Multicenter: 5 CF centers in Canada.
Participants randomized at the time of a pulmonary exacerbation on the basis of results from either
conventional or biofilm antimicrobial susceptibility testing of their Paeruginosa isolate cultured from
the sputum obtained at the screening visit.

Participants

Inclusion criteria: diagnosis of CF, chronic infection with $P$ aeruginosa $(>50 \%$ of respiratory specimens positive in the 24 months prior to screening) and the ability to produce sputum and to reproducibly perform pulmonary function testing; provided written consent.

Exclusion criteria: sputum culture either negative for $P$ aeruginosa or with a density of less than $10^{5}$ $\mathrm{CFU} / \mathrm{mL}$ at screening, history of $B$ cepacia positive respiratory culture within 24 months prior to or at screening, physician's decision to use antibiotics other than those prescribed by the principal investigator (VW), history of allergy to more than 2 classes of antibiotics or anaphylaxis to any antibiotic, status post lung transplantation or listed for lung transplantation, pregnant or clinically unstable.

39 participants with CF: biofilm-treated group ( $n=24,48$ exacerbations) and the conventionally-treated (control) group ( $n=15,26$ exacerbations).

\section{Age: mean (range)}

At first exacerbation: biofilm group 29.4 (11.3 to 49.2) years; control group 22.6 (10.1 to 53.2) years.

All exacerbations: biofilm group 27.2 (10.2 to 49.9) years; control group 20.3 (10.1 to 53.2) years. 
Yau 2014 (Continued)

\section{Gender}

At first exacerbation: biofilm group, 11 males and 13 females; control group, 3 males and 12 females. All exacerbations: biofilm group, 22 males and 26 females; control group, 6 males and 20 females.

\section{Genotype delta F508 homozygous}

At first exacerbation: biofilm group $\mathrm{n}=11(48 \%)$; control group $\mathrm{n}=9(60 \%)$.

All exacerbations: biofilm group $n=26$ (54\%); control group $n=16(61 \%)$.

\section{CFRD}

At first exacerbation: biofilm group $n=8(33 \%)$; control group $n=3(20 \%)$.

All exacerbations: biofilm group $n=12(25 \%)$; control group $n=6(23 \%)$.

\section{Liver disease}

At first exacerbation: biofilm group $\mathrm{n}=3(12 \%)$; control group $\mathrm{n}=0(0 \%)$.

All exacerbations: biofilm group $n=4(8 \%)$; control group $n=0(0 \%)$.

\section{Pancreatic insufficiency:}

At first exacerbation: biofilm group $\mathrm{n}=22(92 \%)$; control group $\mathrm{n}=13(87 \%)$.

All exacerbations: biofilm group $n=45(97 \%)$; control group $n=24(92 \%)$.

ABPA

At first exacerbation: biofilm group $\mathrm{n}=3(12 \%)$; control group $\mathrm{n}=2(13 \%)$.

All exacerbations: biofilm group $n=7(14 \%)$; control group $n=5(19 \%)$.

Baseline $\mathrm{FEV}_{\mathbf{1}} \%$ predicted: mean (range)

At first exacerbation: in the biofilm group was $53.3 \%$ (26.8 to 83.9$)$ and was $60.6 \%$ (25.2 to 98.3 ) in the control group.

All exacerbations: in the biofilm group was $55.7 \%$ (25.6 to 111.3 ) and was $62.4 \%$ (25.2 to 98.3 ) in the control group.

Baseline FEV $\mathbf{~ L}_{\text {: }}$ mean (range)

At first exacerbation: in the biofilm group was 1.9 (0.8 to 3.7) and was 1.9 ( 0.7 to 3.7$)$ in the control group.

All exacerbations: in the biofilm group was 1.9 (0.8 to 4.2$)$ and was 1.9 (0.7 to 3.7$)$ in the control group.

\section{At exacerbation $\mathrm{FEV}_{\mathbf{1}} \%$ predicted: mean (range)}

At first exacerbation: in the biofilm group was $41.8 \%$ (23.9 to 71.1 ) and was $52.9 \%$ (21.2 to 91.0 ) in the control group.

All exacerbations: in the biofilm group was $45.0 \%$ (15.4 to 90.4 ) and was $53.1 \%$ (21.2 to 93.8 ) in the control group.

\section{At exacerbation FEV $\mathbf{1}$ L: mean (range)}

At first exacerbation: in the biofilm group was 1.4 (0.6 to 3.1) and was 1.7 (0.6 to 3.2) in the control group.

All exacerbations: in the biofilm group was 1.5 (0.6 to 3.4) and was 1.7 (0.5 to 3.5) in the control group.

\section{BMI $\left(\mathrm{kg} / \mathrm{m}^{2}\right)$ at baseline: mean (range)}

At first exacerbation: in the biofilm group was 21.1 (14.6 to 30.1) and was 19.7 (14.2 to 26.8) in the control group. 
Yau 2014 (Continued)

All exacerbations: in the biofilm group was 20.6 (14.5 to 30.1) and was 19.2 (14.2 to 26.8) in the control group.

\section{BMI $\left(\mathrm{kg} / \mathrm{m}^{2}\right)$ at exacerbation: mean (range)}

At first exacerbation: in the biofilm group was 20.6 (13.5 to 27.9$)$ and was 18.8 (13.9 to 23.0) in the control group.

All exacerbations: in the biofilm group was 20.2 (13.5 to 27.9$)$ and was 18.5 (13.9 to 23.7) in the control group.

\section{Maintenance treatment: dornase alfa}

At first exacerbation: biofilm group $\mathrm{n}=11$ (46\%); control group $\mathrm{n}=7(47 \%)$.

All exacerbations: biofilm group $n=28(58 \%)$; control group $n=16(61 \%)$.

\section{Maintenance treatment: azithromycin}

At first exacerbation: biofilm group $n=14(58 \%)$; control group $n=4(27 \%)$.

All exacerbations: biofilm group $\mathrm{n}=11(42 \%)$; control group $\mathrm{n}=30(62 \%)$.

Maintenance treatment: inhaled tobramycin

At first exacerbation: biofilm group $\mathrm{n}=18(75 \%)$; control group $\mathrm{n}=12(80 \%)$.

All exacerbations: biofilm group $n=36$ (75\%); control group $n=20$ (77\%).

\section{Maintenance treatment: hypertonic saline}

At first exacerbation: biofilm group $n=4(17 \%)$; control group $n=2(13 \%)$.

All exacerbations: biofilm group $n=11(23 \%)$; control group $n=3(11 \%)$.

\section{Maintenance treatment: other inhaled antibiotics}

At first exacerbation: biofilm group $n=2(8 \%)$; control group $n=2(13 \%)$.

All exacerbations: biofilm group $n=8(17 \%)$; control group $n=5(19 \%)$. ceptibility testing of their $P$ aeruginosa isolate cultured from their most recent sputum.

Outcomes

Primary outcome: proportion of exacerbations in the biofilm versus conventional group in which $a \geq$ $3 \log _{10}$ drop in sputum density of $P$ aeruginosa in CFU/mL from Day 0 to Day 14 of antibiotic treatment, was achieved.

Secondary outcomes: pulmonary function tests (FEV $1, F V C), C F Q-R$, serum WBC, CRP, ESR and sputum IL-8 and neutrophil elastase measured at Day 0, Day 14 of antibiotic therapy and at the 1-month follow-up visit.

Notes

\section{Risk of bias}

Bias Authors' judgement Support for judgement

Random sequence genera- Low risk tion (selection bias)
Co-PI randomized participants according to a random numbers table generated for each site based on the expected number of PEx during the study period. If a participant developed a second PEx during the study period they were rerandomized to 1 of the 2 study arms (information provided in supplementary material).
The method of selection (based on conventional or biofilm testing) was blinded to all participants, the treating team and all study personnel with the exception of co-PI (YY) who was not directly involved in any patient care. 
Yau 2014 (Continued)

Blinding of participants Low risk_ "Although the actual antibiotics themselves were not blinded, the method of and personnel (perforselection (based on conventional or biofilm testing) was blinded to all submance bias)

All outcomes jects, the treating team and all study personnel with the exception of co-PI YY (who was not directly involved in any patient care)."

$\begin{array}{ll}\begin{array}{l}\text { Blinding of outcome as- } \\ \text { sessment (detection bias) }\end{array} & \text { Low risk } \\ \begin{array}{ll}\text { All outcomes } & \text { "Although the actual antibiotics themselves were not blinded, the method of } \\ & \text { selection (based on conventional or biofilm testing) was blinded to all sub- } \\ & \text { jects, the treating team and all study personnel with the exception of co-PI YY } \\ \text { (who was not directly involved in any patient care)." }\end{array}\end{array}$

\begin{tabular}{|c|c|c|}
\hline $\begin{array}{l}\text { Incomplete outcome data } \\
\text { (attrition bias) } \\
\text { All outcomes }\end{array}$ & Low risk & $\begin{array}{l}41 \text { participants randomised, } 39 \text { analysed, } 2 \text { (5\%) excluded (one from each } \\
\text { group) with no data available for either of these. Reasons for exclusion given } \\
-1 \text { from conventional group lost to follow up and } 1 \text { from biofilm group did not } \\
\text { grow } P \text {. aeruginosa on day } 1 \text {. }\end{array}$ \\
\hline
\end{tabular}

\begin{tabular}{lll}
\hline $\begin{array}{l}\text { Selective reporting (re- } \\
\text { porting bias) }\end{array}$ & Low risk & $\begin{array}{l}\text { Protocol accessed from clinicaltrials.gov, all outcomes listed in the protocol } \\
\text { are reported in the full paper. }\end{array}$ \\
\hline Other bias & Low risk & No other potential sources of bias identified. \\
\hline
\end{tabular}

B cepacia: Burkholderia cepacia

BCC: Burkholderia cepacia complex

CF: cystic fibrosis

CFQ-R: Cystic Fibrosis Questionnaire-Revised

CFU: colony forming units

Co-PI: co-primary investigator

CRP: C-reactive protein

ESR: erythrocyte sedimentation rate

$\mathrm{FEF}_{25-75 \%}$ : mid-expiratory flow

$\mathrm{FEV}_{1}$ : forced expiratory volume in 1 second

FVC: forced vital capacity

IV: intravenous

Paeruginosa: Pseudomonas aeruginosa

PEx: pulmonary exacerbation

WBC: white blood cell count

Characteristics of excluded studies [ordered by study ID]

\begin{tabular}{ll}
\hline Study & Reason for exclusion \\
\hline Aaron 2005 & Trial of combination antibiotic susceptibility testing, not the topic of this review. \\
\hline Oermann 2010 & $\begin{array}{l}\text { Trial of antibiotic susceptibility of } P \text { aeruginosa isolates after repeated courses of inhaled aztreon- } \\
\text { am lysine. }\end{array}$ \\
\hline
\end{tabular}

P aeruginosa: Pseudomonas aeruginosa

\section{DATA AND ANALYSES}


Comparison 1. Biofilm testing versus standard testing

\begin{tabular}{|c|c|c|c|c|}
\hline Outcome or subgroup title & $\begin{array}{l}\text { No. of } \\
\text { studies }\end{array}$ & $\begin{array}{l}\text { No. of } \\
\text { partici- } \\
\text { pants }\end{array}$ & Statistical method & Effect size \\
\hline $\begin{array}{l}1 \mathrm{FEV}_{1}(\mathrm{~L}) \text { change from start of treat- } \\
\text { ment }\end{array}$ & 2 & & Mean Difference (IV, Fixed, 95\% CI) & Subtotals only \\
\hline 1.1 At day 7 & 1 & 23 & Mean Difference (IV, Fixed, 95\% CI) & $-0.12[-0.36,0.13]$ \\
\hline 1.2 At day 14 & 2 & 68 & Mean Difference (IV, Fixed, 95\% CI) & $0.04[-0.08,0.16]$ \\
\hline 1.3 At 1 month & 1 & 27 & Mean Difference (IV, Fixed, 95\% CI) & $0.17[-0.03,0.37]$ \\
\hline $\begin{array}{l}2 \mathrm{FEV}_{1}(\% \text { predicted) change from } \\
\text { start of treatment }\end{array}$ & 1 & & Mean Difference (IV, Fixed, 95\% CI) & Subtotals only \\
\hline 2.1 At day 7 & 1 & 23 & Mean Difference (IV, Fixed, 95\% CI) & $-3.09[-10.60,4.41]$ \\
\hline 2.2 At day 14 & 1 & 34 & Mean Difference (IV, Fixed, 95\% CI) & $-2.47[-9.29,4.34]$ \\
\hline 2.3 At 1 month & 1 & 27 & Mean Difference (IV, Fixed, 95\% CI) & $4.93[-2.42,12.28]$ \\
\hline $\begin{array}{l}3 \text { FVC (\% predicted) change from } \\
\text { start of treatment }\end{array}$ & 1 & & Mean Difference (IV, Fixed, 95\% CI) & Subtotals only \\
\hline 3.1 At day 7 & 1 & 23 & Mean Difference (IV, Fixed, 95\% CI) & $-6.35[-13.04,0.34]$ \\
\hline 3.2 At day 14 & 1 & 34 & Mean Difference (IV, Fixed, 95\% CI) & $-2.27[-9.06,4.51]$ \\
\hline 3.3 At 1 month & 1 & 27 & Mean Difference (IV, Fixed, 95\% CI) & $5.8[-4.59,16.19]$ \\
\hline $\begin{array}{l}4 \text { FVC (L) change from start of treat- } \\
\text { ment }\end{array}$ & 1 & & Mean Difference (IV, Fixed, 95\% CI) & Subtotals only \\
\hline 4.1 At day 7 & 1 & 23 & Mean Difference (IV, Fixed, 95\% CI) & $-0.13[-0.42,0.17]$ \\
\hline 4.2 At day 14 & 1 & 34 & Mean Difference (IV, Fixed, 95\% CI) & $-0.03[-0.32,0.26]$ \\
\hline 4.3 At 1 month & 1 & 27 & Mean Difference (IV, Fixed, 95\% CI) & $0.27[-0.07,0.60]$ \\
\hline 5 Time to next exacerbation (days) & 1 & & Hazard Ratio (Fixed, 95\% Cl) & Subtotals only \\
\hline $\begin{array}{l}6 \text { Pulmonary exacerbations (num- } \\
\text { ber of participants) }\end{array}$ & 1 & & Risk Ratio (M-H, Fixed, 95\% Cl) & Subtotals only \\
\hline 6.1 At end of study & 1 & 39 & Risk Ratio (M-H, Fixed, 95\% Cl) & $0.83[0.57,1.22]$ \\
\hline 7 Adverse events & 2 & & Risk Ratio (M-H, Fixed, 95\% Cl) & Subtotals only \\
\hline 7.1 Mild & 2 & 73 & Risk Ratio (M-H, Fixed, 95\% Cl) & $0.70[0.48,1.04]$ \\
\hline 7.2 Moderate & 2 & 73 & Risk Ratio (M-H, Fixed, 95\% Cl) & $0.36[0.07,1.77]$ \\
\hline 7.3 Severe & 2 & 73 & Risk Ratio (M-H, Fixed, 95\% Cl) & $0.0[0.0,0.0]$ \\
\hline
\end{tabular}




\begin{tabular}{|c|c|c|c|c|}
\hline Outcome or subgroup title & $\begin{array}{l}\text { No. of } \\
\text { studies }\end{array}$ & $\begin{array}{l}\text { No. of } \\
\text { partici- } \\
\text { pants }\end{array}$ & Statistical method & Effect size \\
\hline $\begin{array}{l}8 \text { Change in } P \text { aeruginosa sputum } \\
\text { density }\left(\log _{10} \mathrm{CFU} / \mathrm{g}\right)\end{array}$ & 2 & & Mean Difference (IV, Fixed, 95\% CI) & Subtotals only \\
\hline 8.1 At day 14 & 2 & 70 & Mean Difference (IV, Fixed, 95\% CI) & $0.80[-0.59,2.18]$ \\
\hline 8.2 At 1 month & 1 & 30 & Mean Difference (IV, Fixed, 95\% CI) & $0.35[-0.53,1.23]$ \\
\hline $\begin{array}{l}9 \text { CFQ-R change from start of treat- } \\
\text { ment }\end{array}$ & 1 & & Mean Difference (IV, Fixed, 95\% CI) & Subtotals only \\
\hline 9.1 At day 14 & 1 & 38 & Mean Difference (IV, Fixed, 95\% CI) & $-15.05[-28.38,-1.71]$ \\
\hline 9.2 At 1 month & 1 & 27 & Mean Difference (IV, Fixed, 95\% CI) & $-17.03[-30.13,-3.92]$ \\
\hline
\end{tabular}

\section{Analysis 1.1. Comparison 1 Biofilm testing versus standard} testing, Outcome $1 \mathrm{FEV}_{1}$ (L) change from start of treatment.

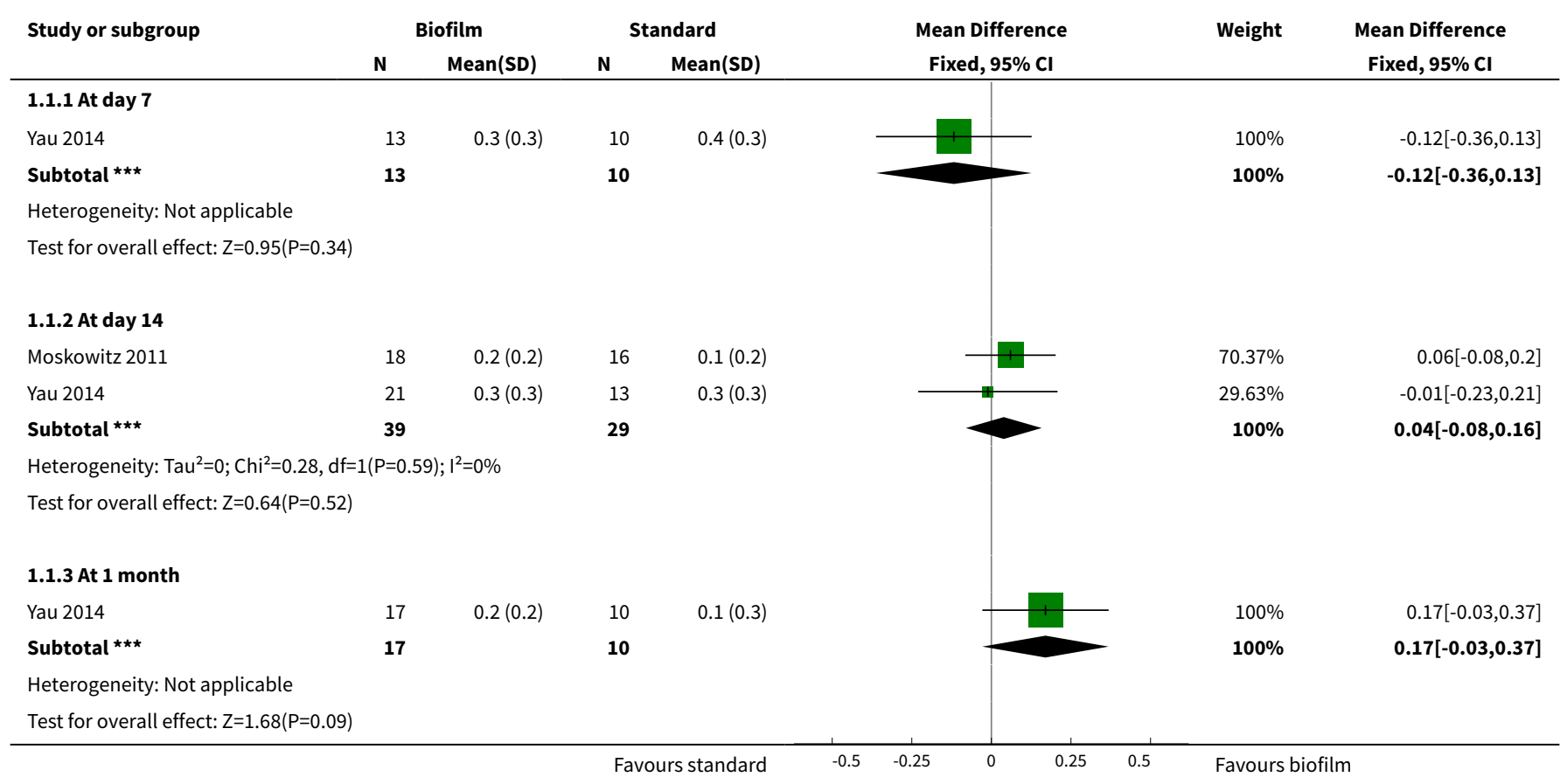

Analysis 1.2. Comparison 1 Biofilm testing versus standard testing, Outcome $2 \mathrm{FEV}_{1}$ (\% predicted) change from start of treatment.

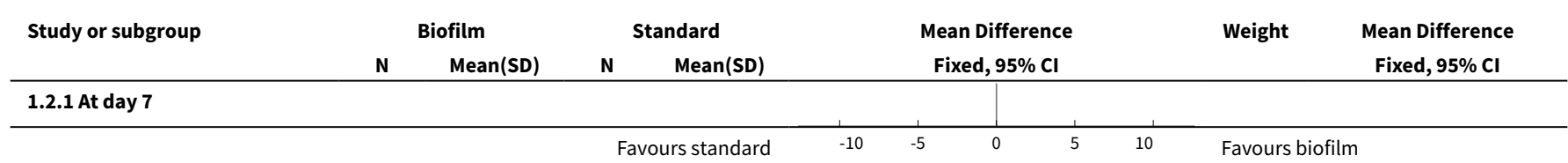




\begin{tabular}{|c|c|c|c|c|c|c|c|c|}
\hline \multirow{3}{*}{$\begin{array}{l}\text { Study or subgroup } \\
\text { Yau } 2014\end{array}$} & \multicolumn{2}{|c|}{ Biofilm } & \multicolumn{2}{|c|}{ Standard } & \multirow{2}{*}{\multicolumn{2}{|c|}{$\begin{array}{c}\text { Mean Difference } \\
\text { Fixed, } 95 \% \mathrm{Cl}\end{array}$}} & \multirow{3}{*}{$\begin{array}{r}\text { Weight } \\
100 \%\end{array}$} & \multirow{3}{*}{$\begin{array}{c}\text { Mean Difference } \\
\text { Fixed, 95\% Cl } \\
-3.09[-10.6,4.41\end{array}$} \\
\hline & \multirow{2}{*}{$\frac{\mathbf{N}}{13}$} & \multirow{2}{*}{$\begin{array}{r}\text { Mean(SD) } \\
7.3(7.6)\end{array}$} & \multirow{2}{*}{$\frac{\mathbf{N}}{10}$} & \multirow{2}{*}{$\frac{\text { Mean(SD) }}{10.4(10.1)}$} & & & & \\
\hline & & & & & & \begin{tabular}{l|l} 
& \\
\end{tabular} & & \\
\hline 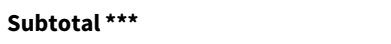 & 13 & & 10 & & & & $100 \%$ & $-3.09[-10.6,4.41]$ \\
\hline \multicolumn{9}{|l|}{ Heterogeneity: Not applicable } \\
\hline \multicolumn{9}{|l|}{ Test for overall effect: $Z=0.81(P=0.42)$} \\
\hline \multicolumn{9}{|l|}{ 1.2.2 At day 14} \\
\hline Yau 2014 & 21 & $7.1(9.4)$ & 13 & $9.6(10.1)$ & & 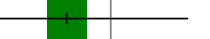 & $100 \%$ & $-2.47[-9.29,4.34]$ \\
\hline Subtotal $* \star \star$ & 21 & & 13 & & & & $100 \%$ & $-2.47[-9.29,4.34]$ \\
\hline \multicolumn{9}{|l|}{ Heterogeneity: Not applicable } \\
\hline \multicolumn{9}{|l|}{ Test for overall effect: $Z=0.71(P=0.48)$} \\
\hline \multicolumn{9}{|l|}{ 1.2.3 At 1 month } \\
\hline Yau 2014 & 17 & $7.5(7.5)$ & 10 & $2.6(10.4)$ & & & $100 \%$ & $4.93[-2.42,12.28]$ \\
\hline 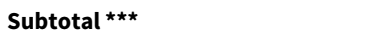 & 17 & & 10 & & & & $100 \%$ & $4.93[-2.42,12.28]$ \\
\hline \multicolumn{9}{|l|}{ Heterogeneity: Not applicable } \\
\hline \multicolumn{9}{|l|}{ Test for overall effect: $Z=1.31(P=0.19)$} \\
\hline & & & $\mathrm{Fal}$ & urs standard & -10 & -5 & Favours & \\
\hline
\end{tabular}

\section{Analysis 1.3. Comparison 1 Biofilm testing versus standard testing, Outcome 3 FVC (\% predicted) change from start of treatment.}

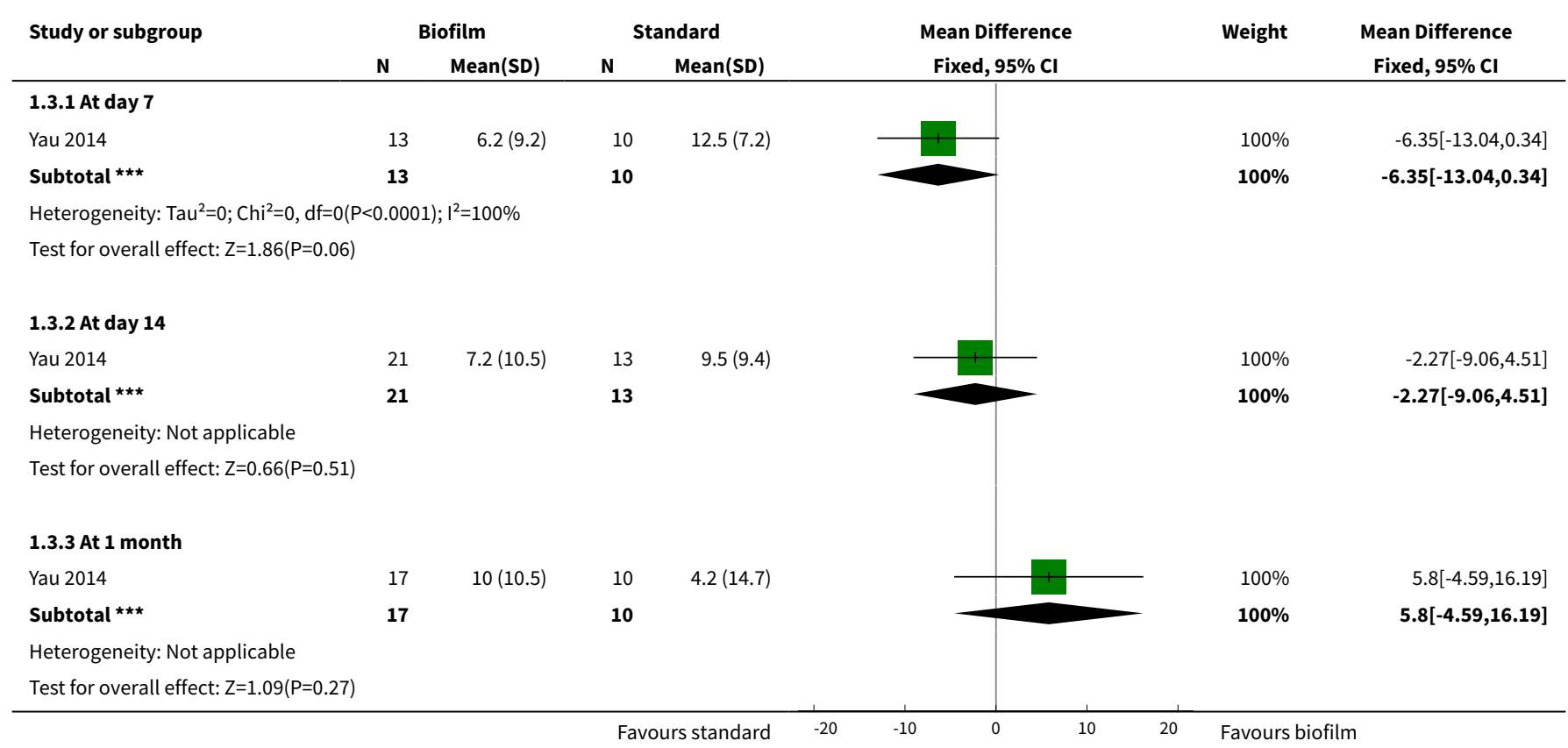


Analysis 1.4. Comparison 1 Biofilm testing versus standard testing, Outcome 4 FVC (L) change from start of treatment.

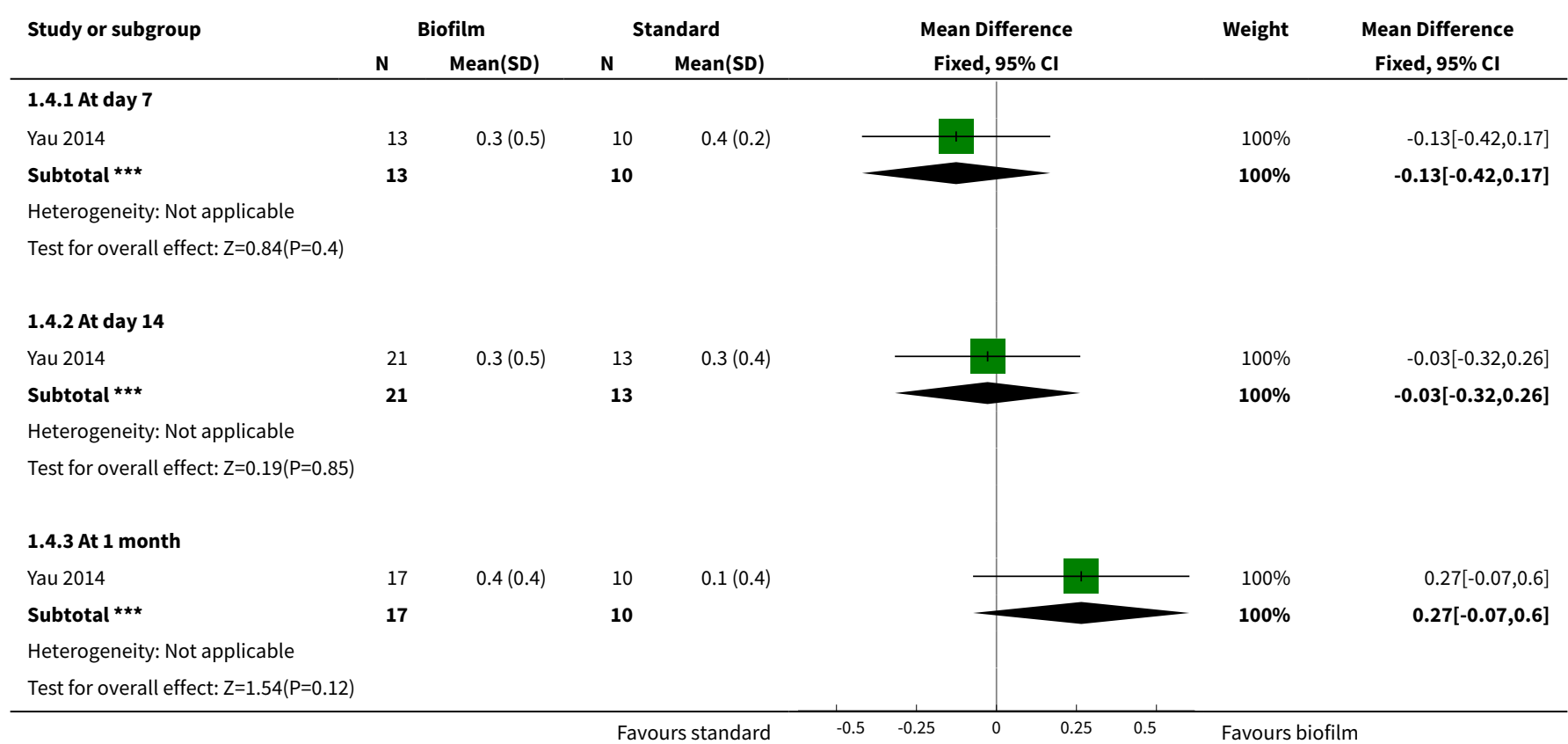

Analysis 1.5. Comparison 1 Biofilm testing versus standard testing, Outcome 5 Time to next exacerbation (days).

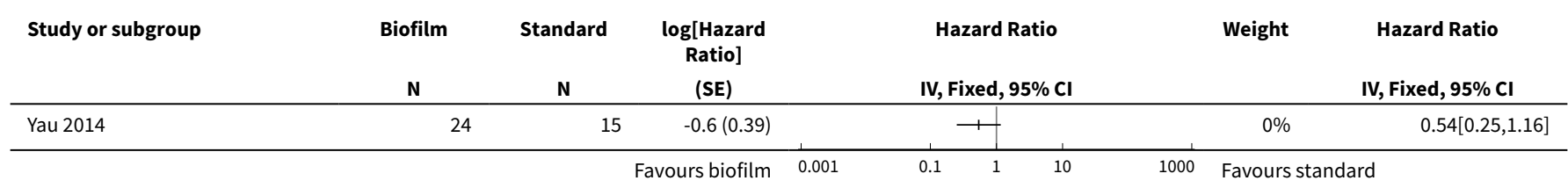

Analysis 1.6. Comparison 1 Biofilm testing versus standard testing, Outcome 6 Pulmonary exacerbations (number of participants).

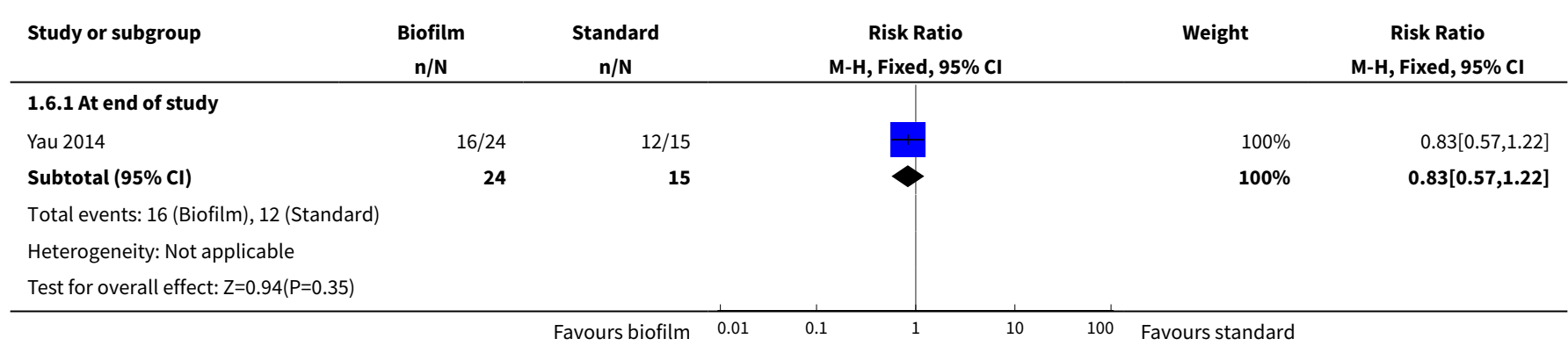


Analysis 1.7. Comparison 1 Biofilm testing versus standard testing, Outcome 7 Adverse events.

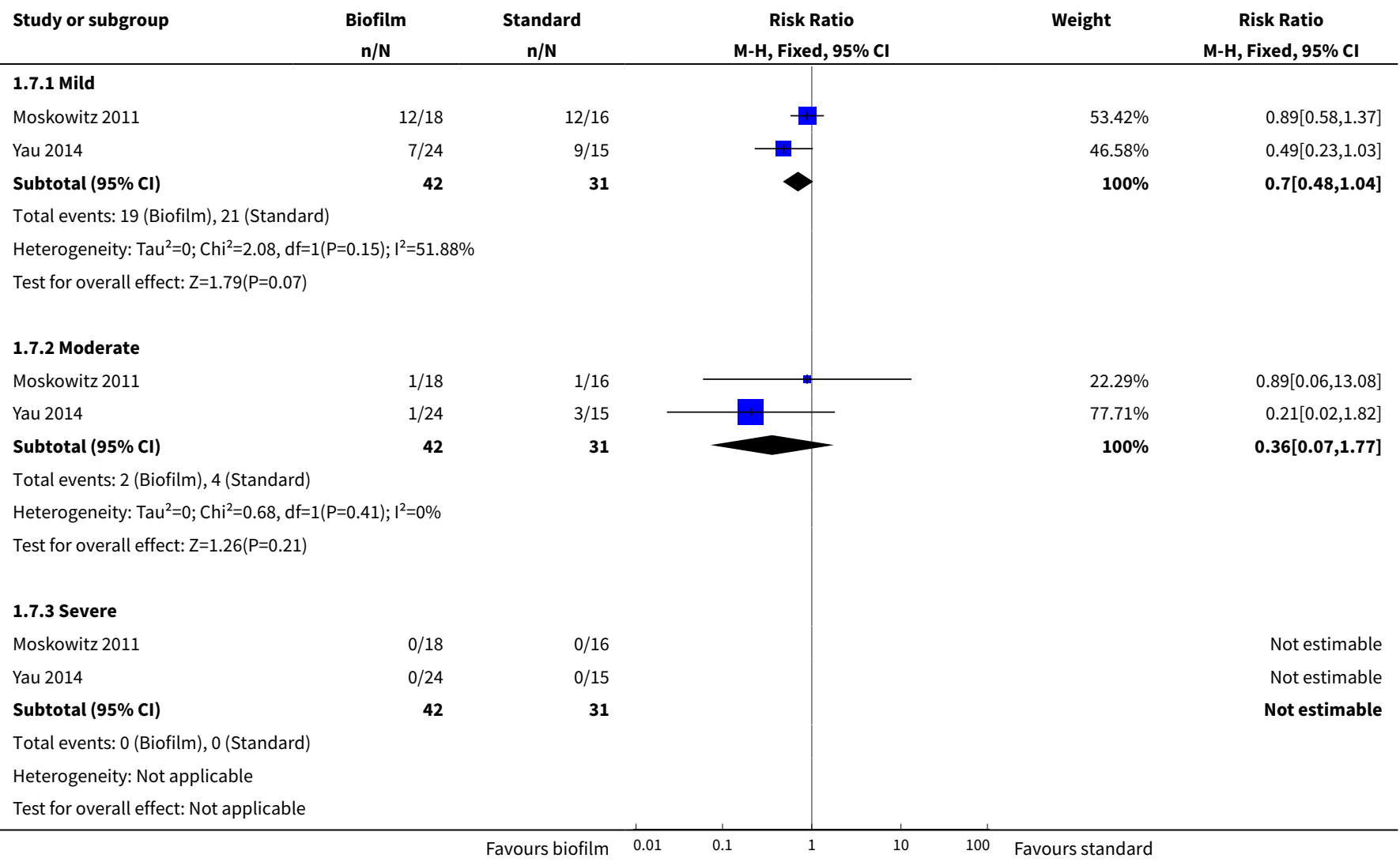

Analysis 1.8. Comparison 1 Biofilm testing versus standard testing, Outcome 8 Change in $P$ aeruginosa sputum density $\left(\log _{10} \mathrm{CFU} / \mathrm{g}\right)$.

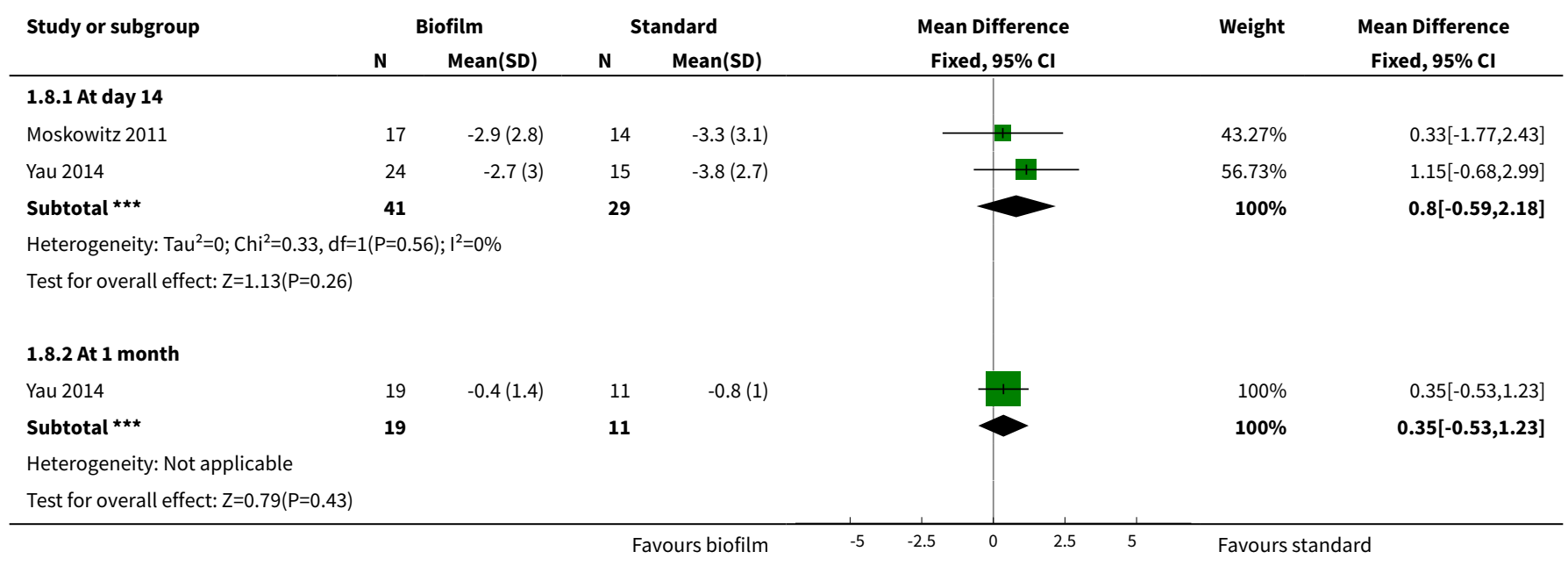


Analysis 1.9. Comparison 1 Biofilm testing versus standard testing, Outcome 9 CFQ-R change from start of treatment.

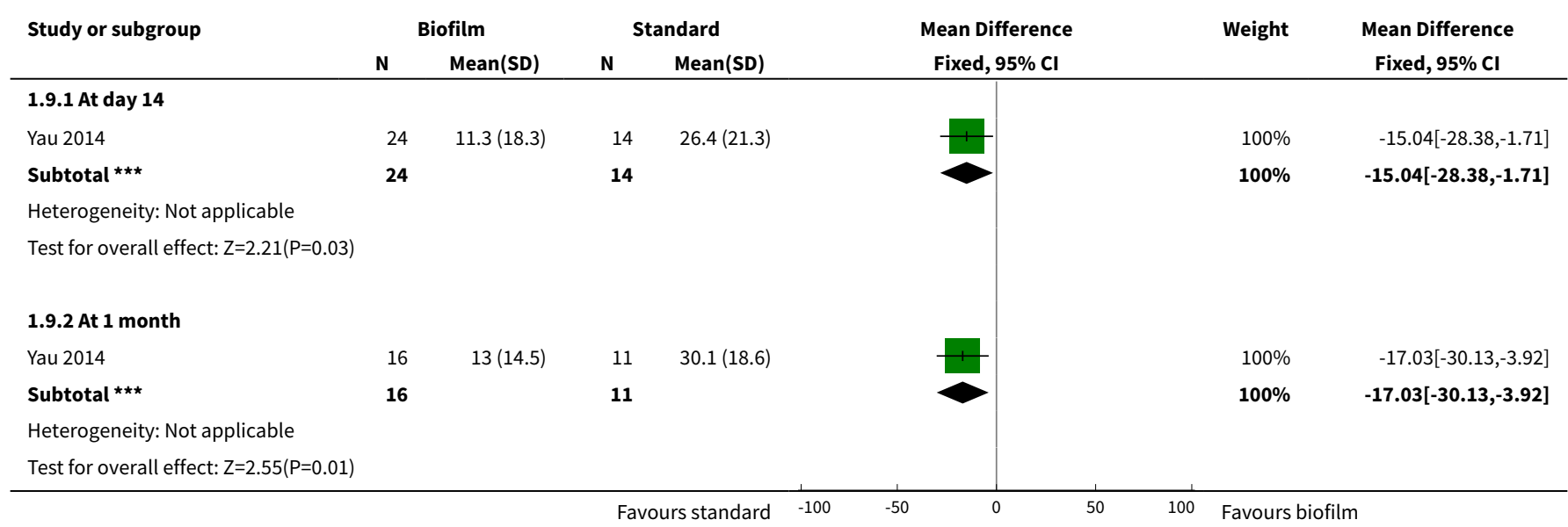

\section{WHAT'S NEW}

\begin{tabular}{lll}
\hline Date & Event & Description \\
\hline 19 March 2020 & Amended & Clarification statement added from Alan Smyth, Co-ordinating \\
& Editor on 19 March 2020: This review was found by the Cochrane \\
& Funding Arbiters, post-publication, to be noncompliant with the \\
& Cochrane conflict of interest policy, which includes the relevant \\
& parts of the Cochrane Commercial Sponsorship Policy. The re- \\
& view will be updated by August 2020; both authors of the future \\
& update will be free of conflicts. \\
\hline
\end{tabular}

\section{H I S T O R Y}

Protocol first published: Issue 12, 2011

Review first published: Issue 11, 2012

\begin{tabular}{lll}
\hline Date & Event & Description \\
\hline 26 September 2017 & $\begin{array}{l}\text { New citation required but conclusions } \\
\text { have not changed }\end{array}$ & $\begin{array}{l}\text { No new data have been added to this update so our conclusions } \\
\text { remain the same. }\end{array}$ \\
\hline
\end{tabular}

26 September $2017 \quad$ New search has been performed A search of the Cystic Fibrosis and Genetic Disorders Review Group's Cystic Fibrosis Trials Register identified four new references to an already included study (Yau 2014). No new studies were identified in the searches of ongoing trials registries.

A summary of findings table has been added to the review.

\begin{tabular}{lll}
\hline 25 February 2015 & $\begin{array}{l}\text { New citation required but conclusions } \\
\text { have not changed }\end{array}$ & $\begin{array}{l}\text { Despite the inclusion of a new trial, our conclusions remain the } \\
\text { same. }\end{array}$ \\
\hline 25 February 2015 & New search has been performed & $\begin{array}{l}\text { A search of the Cystic Fibrosis \& Genetic Disorders Group's Cystic } \\
\text { Fibrosis Trials Register identified three new references to a single }\end{array}$
\end{tabular}




\begin{tabular}{lll}
\hline Date Event Description & Den
\end{tabular}

trial which was included in the review (Yau 2014). In the original review, this trial had been identified and listed as ongoing.

\section{CONTRIBUTIONS OFAUTHORS}

\begin{tabular}{ll}
\hline Roles and responsibilities & \\
\hline TASK & WHO WILL UNDERTAKE THE TASK? \\
\hline Protocol stage: draft the protocol & Valerie Waters \\
\hline Review stage: select which trials to include $(2+1$ arbiter $)$ & Valerie Waters and Felix Ratjen (+ Nikki Jahnke) \\
\hline Review stage: extract data from trials ( 2 people) & Valerie Waters and Felix Ratjen \\
\hline Review stage: enter data into RevMan & Valerie Waters \\
\hline Review stage: carry out the analysis & Valerie Waters and Felix Ratjen \\
\hline Review stage: interpret the analysis & Valerie Waters and Felix Ratjen \\
\hline Review stage: draft the final review & Valerie Waters and Felix Ratjen \\
\hline Update stage: update the review & Valerie Waters and Felix Ratjen \\
\hline
\end{tabular}

\section{DECLARATIONS OF INTEREST}

Both authors of this review are investigators in the included biofilm trial which was funded by a grant from Innovotech Inc. and the National Research Council Industrial Research Assistance Program (NRC-IRAP) of Alberta (Yau 2014). The funders had no involvement in the trial design, interpretation of data, writing of the manuscript or decision to submit the manuscript for publication.

Clarification statement added from Alan Smyth, Co-ordinating Editor on 19 March 2020: This review was found by the Cochrane Funding Arbiters, post-publication, to be noncompliant with the Cochrane conflict of interest policy, which includes the relevant parts of the Cochrane Commercial Sponsorship Policy. The review will be updated by August 2020; both authors of the future update will be free of conflicts.

\section{SOURCES OF SUPPORT}

\section{Internal sources}

- No sources of support supplied

\section{External sources}

- National Institute for Health Research, UK.

This systematic review was supported by the National Institute for Health Research, via Cochrane Infrastructure funding to the Cochrane Cystic Fibrosis and Genetic Disorders Group.

\section{DIFFERENCES BETWEEN PROTOCOLANDREVIEW}

In a post hoc change the review authors additionally decided to report data as change from start of treatment and not just absolute values for their primary outcome of lung function as these data are more useful to users of the review than just endpoint values which do not relate to previous levels of lung function. Furthermore, a summary of findings table has been added in line with Cochrane guidance (2017). 


\section{N D EX TERMS}

\section{Medical Subject Headings (MeSH)}

Anti-Bacterial Agents [*therapeutic use]; Biofilms [ ${ }^{*}$ drug effects] [growth \& development]; Cystic Fibrosis [ ${ }^{*}$ complications]; Microbial Sensitivity Tests [methods]; Pseudomonas Infections [ ${ }^{*}$ drug therapy]; Pseudomonas aeruginosa [ ${ }^{*}$ drug effects] [physiology]; Randomized Controlled Trials as Topic; Respiratory Tract Infections [*drug therapy] [microbiology]; Sputum [microbiology]

\section{MeSH check words}

Adolescent; Adult; Female; Humans; Male 